\title{
Defective sarcoplasmic reticulum-mitochondria calcium exchange in aged mouse myocardium
}

\author{
C Fernandez-Sanz ${ }^{1}$, M Ruiz-Meana ${ }^{*, 1}$, E Miro-Casas ${ }^{1}$, E Nuñez ${ }^{2}$, J Castellano ${ }^{1}$, M Loureiro ${ }^{2}$, I Barba ${ }^{1}$, M Poncelas ${ }^{1}$, \\ A Rodriguez-Sinovas ${ }^{1}$, J Vázquez ${ }^{2}$ and D Garcia-Dorado ${ }^{1}$
}

Mitochondrial alterations are critically involved in increased vulnerability to disease during aging. We investigated the contribution of mitochondria-sarcoplasmic reticulum (SR) communication in cardiomyocyte functional alterations during aging. Heart function (echocardiography) and ATP/phosphocreatine (NMR spectroscopy) were preserved in hearts from old mice ( $>20$ months) with respect to young mice (5-6 months). Mitochondrial membrane potential and resting $\mathrm{O}_{2}$ consumption were similar in mitochondria from young and old hearts. However, maximal ADP-stimulated $\mathrm{O}_{2}$ consumption was specifically reduced in interfibrillar mitochondria from aged hearts. Second generation proteomics disclosed an increased mitochondrial protein oxidation in advanced age. Because energy production and oxidative status are regulated by mitochondrial $\mathrm{Ca}^{2+}$, we investigated the effect of age on mitochondrial $\mathrm{Ca}^{2+}$ uptake. Although no age-dependent differences were found in $\mathrm{Ca}^{2+}$ uptake kinetics in isolated mitochondria, mitochondrial $\mathrm{Ca}^{2+}$ uptake secondary to $\mathrm{SR} \mathrm{Ca}^{2+}$ release was significantly reduced in cardiomyocytes from old hearts, and this effect was associated with decreased $N A D(P) H$ regeneration and increased mitochondrial ROS upon increased contractile activity. Immunofluorescence and proximity ligation assay identified the defective communication between mitochondrial voltage-dependent anion channel and SR ryanodine receptor (RyR) in cardiomyocytes from aged hearts associated with altered $\mathrm{Ca}^{2+}$ handling. Age-dependent alterations in $\mathrm{SR} \mathrm{Ca}^{2+}$ transfer to mitochondria and in $\mathrm{Ca}^{2+}$ handling could be reproduced in cardiomyoctes from young hearts after interorganelle disruption with colchicine, at concentrations that had no effect in aged cardiomyocytes or isolated mitochondria. Thus, defective SR-mitochondria communication underlies inefficient interorganelle $\mathrm{Ca}^{2+}$ exchange that contributes to energy demand/supply mistmach and oxidative stress in the aged heart.

Cell Death and Disease (2014) 5, e1573; doi:10.1038/cddis.2014.526; published online 18 December 2014

Age is the main independent risk factor for cardiovascular morbidity and mortality. ${ }^{1}$ It increases heart vulnerability to cardiac diseases as well as the severity of their clinical manifestations, and reduces the efficacy of cardioprotective interventions. ${ }^{2}$ At the cellular level, some of the structural and functional age-dependent changes resemble those of failing cardiac myocytes. ${ }^{3,4}$ Specifically, disturbed $\mathrm{Ca}^{2+}$ homeostasis and excitation-contraction coupling, ${ }^{5}$ as well as deficient mitochondrial energetics ${ }^{6}$ and excessive ROS production, ${ }^{7}$ have been consistently reported in senescent cardiomyocytes. These subcellular alterations likely contribute to the reduced adaptive capacity to stress (exercise, $\beta$-adrenergic stimulation) and increased vulnerability to disease of the aged hearts.

In cardiac cells, electrochemical coupling and metabolic adaptations are based upon the coordination between sarcoplasmic reticulum (SR) and mitochondria tightly interconnected forming an interface to support local ionic exchange and signal transduction in a beat-to-beat basis. ${ }^{8}$ This privileged interorganelle communication facilitates mitochondrial ATP transport for $\mathrm{SR} \mathrm{Ca}^{2+}$ cycling and ensures energy replenishment by reciprocal $\mathrm{Ca}^{2+}$ and ADP exchange. $\mathrm{Ca}^{2+}$ is taken up by mitochondria using a low-affinity uniporter whose activity is driven by the elevated $\mathrm{Ca}^{2+}$ concentration in the microenvironment present around ryanodine receptors (RyR). ${ }^{9}$ Indeed, the kinetics of mitochondrial $\mathrm{Ca}^{2+}$ uptake is more dependent on the concentration of $\mathrm{Ca}^{2+}$ at the SRmitochondria contact points than on bulk cytosolic $\mathrm{Ca}^{2+}$ concentration. ${ }^{8}$ Mitochondrial $\mathrm{Ca}^{2+}$ uptake allows energy supply-demand matching through the activation of Krebs cycle dehydrogenases and electron transport chain activity, and at the same time it regulates the regeneration of Krebscoupled antioxidative defenses $(\mathrm{NAD}(\mathrm{P}) \mathrm{H}) .{ }^{10}$

Defective SR-mitochondria cross talk has been causally linked to the abnormal mitochondrial $\mathrm{Ca}^{2+}$ uptake in failing hearts and may underlie their increased oxidative stress. ${ }^{11}$ Also, in diabetic cardiomyopathy, intracellular $\mathrm{Ca}^{2+}$ overload and depletion of energy stores appear to develop as a consequence of sequential SR-mitochondria dysfunction. ${ }^{12}$ Atrial fibrillation has been associated with an increased fusion

\footnotetext{
${ }^{1}$ Cardiología, Hospital Universitari Vall d'Hebron, Institut de Recerca, Universitat Autònoma de Barcelona, Barcelona, Spain and ${ }^{2}$ Centro Nacional de Investigaciones Cardiovasculares, Madrid, Spain

*Corresponding author: M Ruiz-Meana, Cardiología, Hospital Universitari Vall d'Hebron, Institut de Recerca, Universitat Autònoma de Barcelona, Pg Vall d'Hebron 119-129, 08035 Barcelona, Spain. Tel: +34 93489 4037; Fax: +34 93489 4032; E-mail: mrmeana@ir.vhebron.net

Abbreviations: a.u., arbitrary units ; a.u.f., arbitrary units of fluorescence; CS, citrate synthase; DNP, dinitrophenol; GSH, glutathione; GSSG, glutathione disulfide; IFM, interfibrillar mitochondria; LVEF, left ventricular ejection fraction; LVEDD, left ventricular end-diastolic diameter; LVESD, left ventricular end-systolic diameter; MAM, mitochondria-associated membranes; PLA, proximity ligation assay; PWT, posterior wall thickness; RCR, respiratory control rate; RyR, ryanodine receptor; SSM, subsarcolemmal mitochondria; SWT, septum wall thickness; TBS, tris-buffered saline; VDAC, voltage-dependent anion channel

Received 01.8.14; revised 21.10.14; accepted 04.11.14; Edited by RA Knight
} 
of mitochondria and a subsequent increased colocalization of giant mitochondria with SR, a subcellular remodeling process that contributes to the perpetuation of the arrhythmia. ${ }^{13}$ Because mitochondria are highly dynamic structures, some molecular links have been proposed to provide a stable physical interorganelle bridge ${ }^{14,15}$ while others appear to facilitate direct tunneling of $\mathrm{Ca}^{2+}$ and other signaling mediators. ${ }^{16}$ In the present study, we hypothesized that aging may negatively impact on mitochondria-SR communication by mechanisms involving defective $\mathrm{Ca}^{2+}$ transmission, and we identified reduced physical interaction between RyR and mitochondrial voltage-dependent anion channel (VDAC) as the main responsible of this effect.

\section{Results}

Aging phenotype. Echocardiographic analysis showed thinner ventricular wall and a trend toward increased LV end-diastolic volume in old mice, as well as a nonsignificant trend toward reduced ejection fraction (Table 1). Isolated cardiomyocytes from aged hearts displayed an increase in lysosome vesicles, lipofuscin pigment and $\beta$-galactosidase $(\beta$-gal) activity, as hallmarks of cell senescence (Figure 1). There were no age-dependent differences in mitochondrial pool, as quantified by Mitotracker red staining, quantification of citrate synthase (CS) activity and total cardiac mitochondrial yield (Figure 1).

\section{Effect of aging on energy metabolism and mitochondrial} respiration. Myocardial ATP/phosphocreatine ratio was similar in hearts from both age groups. Advanced age did not induce mitochondrial membrane depolarization under resting conditions as quantified in $\mathrm{JC}-1$ loaded isolated cardiomyocytes (Figure 2a). Both $\mathrm{O}_{2}$ consumption at rest (state-2) and after ADP-stimulation (state-3) were largely preserved in subsarcolemmal mitochondria from aged mouse hearts, independently of the substrates used to feed the respiratory complexes, except a slight decrease in complex 1-mediated state-3 respiration, without changes in respiratory

Table 1 Echocardiographic study of young and old mice

\begin{tabular}{lccc}
\hline & $\begin{array}{c}\text { Young }(\boldsymbol{n}=\mathbf{1 2}) \\
\text { Mean } \pm \text { S.E.M. }\end{array}$ & $\begin{array}{c}\text { Old }(\boldsymbol{n}=\mathbf{1 4}) \\
\text { Mean } \pm \text { S.E.M. }\end{array}$ & $\boldsymbol{P}$ \\
\hline Body weight (g) & $38.30 \pm 4.00$ & $34.59 \pm 1.90$ & 0.41 \\
SWT (mm) & $0.87 \pm 0.05$ & $0.79 \pm 0.021$ & 0.19 \\
PWT (mm) & $0.88 \pm 0.04$ & $0.72 \pm 0.029$ & $0.004^{*}$ \\
LVEDD (mm) & $4.09 \pm 0.17$ & $4.30 \pm 0.174$ & 0.39 \\
LVEDDIN (mm/g) & $0.12 \pm 0.01$ & $0.13 \pm 0.009$ & 0.17 \\
PWT/LVEDD & $0.22 \pm 0.01$ & $0.17 \pm 0.01$ & $0.016^{*}$ \\
SWT/LVEDD & $3.13 \pm 0.2$ & $3.75 \pm 0.25$ & 0.07 \\
LVm (mg) & $115.42 \pm 11.89$ & $100.98 \pm 6.25$ & 0.25 \\
EDLVol (mL) & $46.98 \pm 4.1$ & $55.12 \pm 4.29$ & 0.37 \\
LVm/EDLvol & $3.32 \pm 0.15$ & $1.88 \pm 0.08$ & $0.014^{*}$ \\
(mg/mL) & & & \\
LVEF (\%) & $71.01 \pm 2.73$ & $66.85 \pm 2.06$ & 0.22 \\
HR (b.p.m.) & $455.45 \pm 9.75$ & $436.36 \pm 3.24$ & 0.32 \\
& & & \\
\hline
\end{tabular}

EDLVvol, end-diastolic left ventricular volume; HR, heart rate; LVEDD, left ventricular end-diastolic diameter; LVEDDIN, LVEDD indexed by weight; LVEF, left ventricular ejection fraction; LVm, left ventricular mass; PWT, posterior wall thickness; SWT, septum wall thickness; b.p.m., beats per minute control rate (RCR; Figure 2b). By contrast, interfibrillar mitochondria (IFM) from aged hearts displayed a depression of ADP-stimulated $\mathrm{O}_{2}$ consumption for any substrate used to feed respiratory complexes, with reduced RCR dependent on complexes 1 and 3 (Figure 2b). These data indicate an altered capacity of IFM from aged hearts to respond to maximal stimulation, despite of preserved respiration under resting conditions.

Aging is associated with altered SR RyR gating properties. Field stimulation of cardiomyocytes disclosed a reduction in the amplitude of SR $\mathrm{Ca}^{2+}$ transients and a decreased rate of $\mathrm{Ca}^{2+}$ rise in cardiomyocytes from old hearts, without differences in the time to peak or time to $50 \%$ decay (Figure 3a). SR $\mathrm{Ca}^{2+}$ content, quantified as maximal caffeine-induced $\mathrm{Ca}^{2+}$ release, was similar in cardiomyocytes from both age groups (Figure 3a). In non-stimulated cardiomyocytes, aging was associated with a significant increase in the frequency of spontaneous $\mathrm{SR} \mathrm{Ca}^{2+}$ sparks with decreased $\mathrm{Ca}^{2+}$ diffusion, without changes in their rate or amplitude (Figure 3b). These data indicate altered RyR gating properties in old cardiomyocytes.

Advanced age depresses $\mathrm{SR}$-mitochondria calcium
transfer and $\mathrm{NAD}(\mathrm{P}) \mathrm{H}$ regeneration. In digitoninpermeabilized cardiomyocytes from young hearts, induction of $\mathrm{SR} \mathrm{Ca}^{2+}$ release with caffeine was followed by a rapid increase in mitochondrial $\mathrm{Ca}^{2+}$ uptake that was severely depressed in cardiomyocytes from old hearts (Figure 4a). $\mathrm{Ca}^{2+}$ uptake by mitochondria was dependent on mitochondrial $\mathrm{Ca}^{2+}$ uniporter and could be prevented by the specific inhibitor Ru360 (Figure 4b). However, this depression in mitochondrial $\mathrm{Ca}^{2+}$ uptake kinetics observed in intact cardiomyocytes of aged hearts could not be reproduced in isolated mitochondria exposed to an external $\mathrm{Ca}^{2+}$ pulse in vitro (Figure 4c). Field stimulation at $1 \mathrm{~Hz}$ did not result in net consumption of $\mathrm{NAD}(\mathrm{P}) \mathrm{H}$ in cardiomyocytes from any group of age, but rather induced a slight increase in young cells. However, acceleration of electrical pacing from $1 \mathrm{~Hz}$ to $5 \mathrm{~Hz}$ was associated with a decay in $\mathrm{NAD}(\mathrm{P}) \mathrm{H} / \mathrm{NAD}(\mathrm{P})+$ in cardiomyocytes from old hearts but not from young hearts, indicating an inefficient $\mathrm{NAD}(\mathrm{P}) \mathrm{H}$ regeneration (Figure $4 \mathrm{~d}$ ).

All together, these data suggest a defective $\mathrm{Ca}^{2+}$ transfer from SR to mitochondria, with concomitant reduced bioenergetic feedback response ( $\mathrm{NAD}(\mathrm{P}) \mathrm{H}$ regeneration), in cardiomyocytes of aged hearts, despite normal mitochondrial $\mathrm{Ca}^{2+}$ uniporter activity.

Aged cardiomyocytes have less glutathione and increased mitochondrial ROS production. Total glutathione (GSH) levels (GSHtot) quantified in myocardial tissue were significantly decreased in aging hearts (Figure $4 \mathrm{e}$, left panel). The oxidized fraction of $\mathrm{GSH}$ (glutathione disulfide, GSSG) showed a trend toward an increase in the aging myocardium (Figure 4e, left panel). In isolated cardiomyocytes submitted to electrical stimulation, aging was associated with a significant increase in the shortterm mitochondrial ROS production during high frequency pacing $(5 \mathrm{~Hz})$. There was a nonsignificant trend toward an increased cytosolic ROS levels in aging cardiomyocytes after 
a
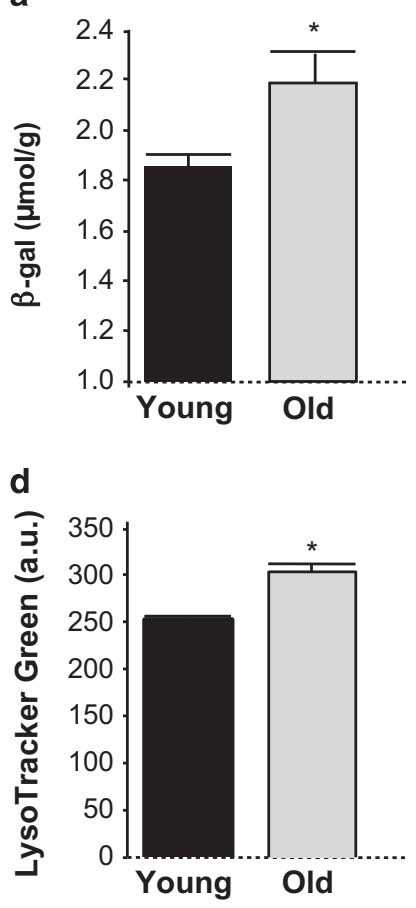

b

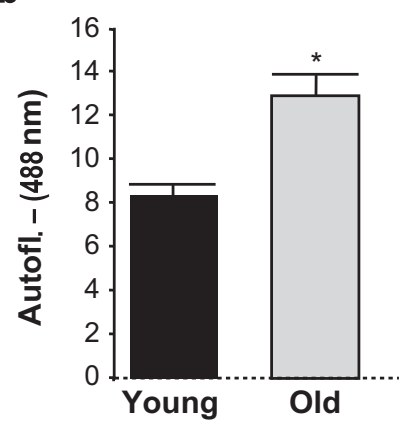

e

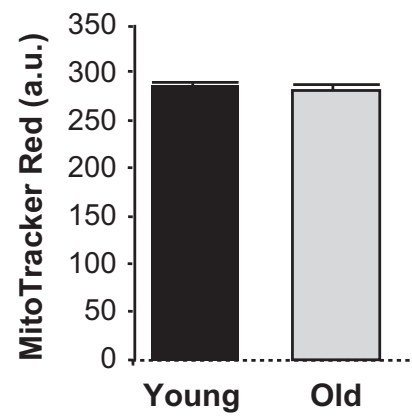

C

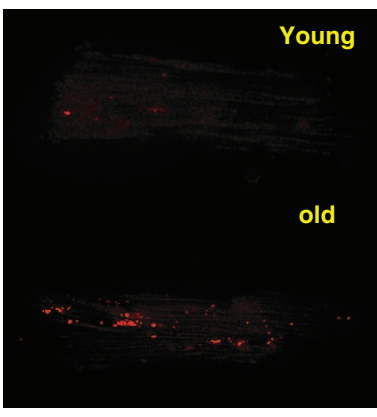

f

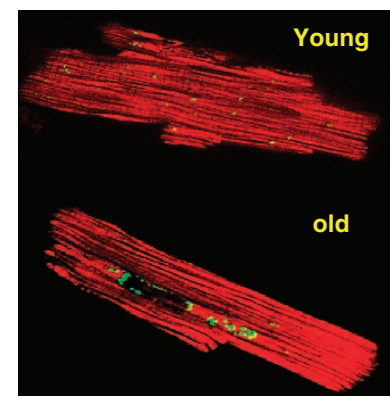

g

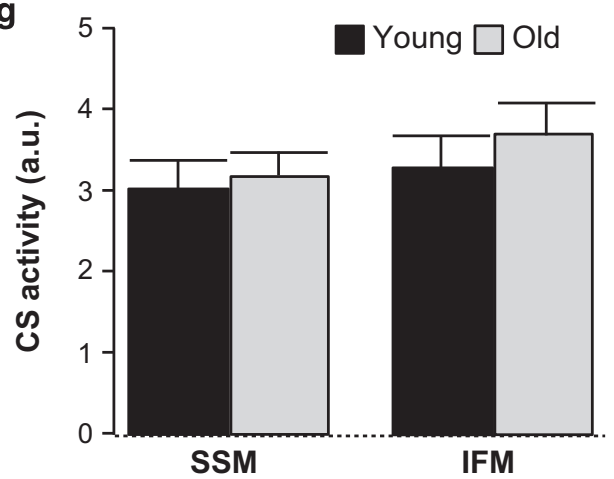

h

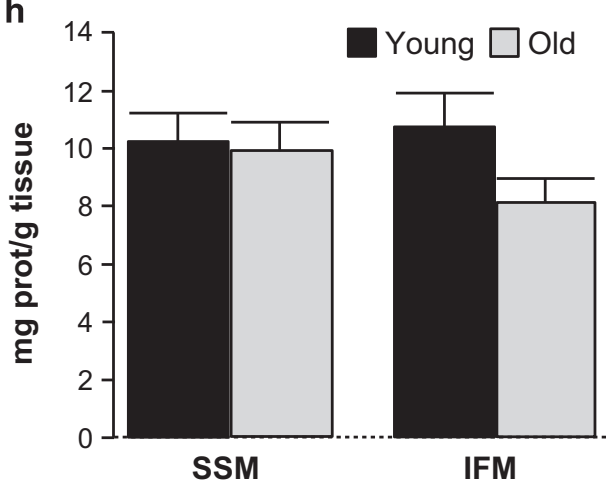

Figure 1 Effect of advanced age on (a) $\beta$-galactosidase, (b and $\mathbf{c})$ lipofuscin autofluorescence, (d and f $\mathbf{f}$, green color) lysosome vesicles, (e and f, red color) mitochondrial pool labeling in intact mouse cardiomyocytes, (g) citrate synthase (CS) activity in isolated heart mitochondria and (h) mitochondrial yield determined as mitochondrial protein with respect to total cardiac protein in subsarcolemmal (SSM) and interfibrillar (IFM) mitochondria isolated from mouse hearts. Mean \pm S.E.M. from $n=14-25$ replicates (5-10 hearts)

high frequency pacing, but we cannot rule out that this is due to diffusion of mitochondrial ROS toward the cytosolic.

Spatial proximity between mitochondria and SR decreases with aging. Simultaneous immunolabeling of permeabilized cardiomyocytes with anti-RyR and anti-VDAC disclosed a pattern of close proximity and similar spatial organization between SR and mitochondria (Figure 5a). Blind quantification of immunocolocalization degree by Mander's coefficient analysis revealed an age-dependent reduction of the fraction of RyR overlapping with VDAC (m1) without significant differences in either RyR or VDAC total fluorescences (Figure 5b). Proximity ligation assay (PLA), specifically addressed to quantify SR-mitochondria clusters of $<40 \mathrm{~nm}$ distance, demonstrated an age-dependent reduction in the positive amplification fluorescent spots (Figures $5 c$ and d).
These data indicate a reduction in the fraction of SR RyR closely juxtaposed with mitochondrial VDAC.

The effect of age on SR-mitochondria dissociation was not explained by a reduced expression of the main proteins postulated to tether both organelles. Western blot quantification of mitofusin-2, VDAC1, RyR2 and Grp75 in total cardiac homogenates, microsomal fractions and mitochondria showed no differences between both groups of age (Figure 5e). These results were consistent with those of quantitative proteomics analysis (not shown). However, individual peptide quantification by GELSILOX of the same data revealed an increase in the proportion of peptides containing oxidized Cys detected in mitochondrial VDAC and a concomitant reduction in the same peptides containing the reduced Cys form in both subsarcolemmal (SSM) and IFM from old mouse hearts, suggesting that aging induces 
a

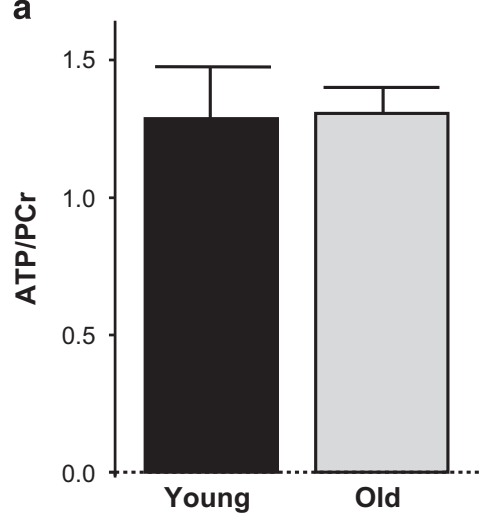

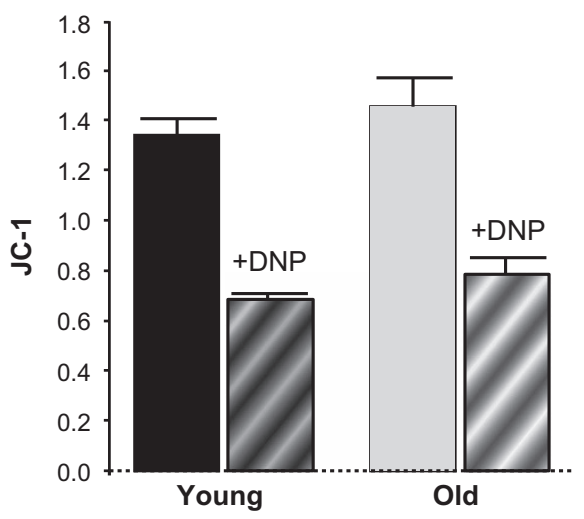

b
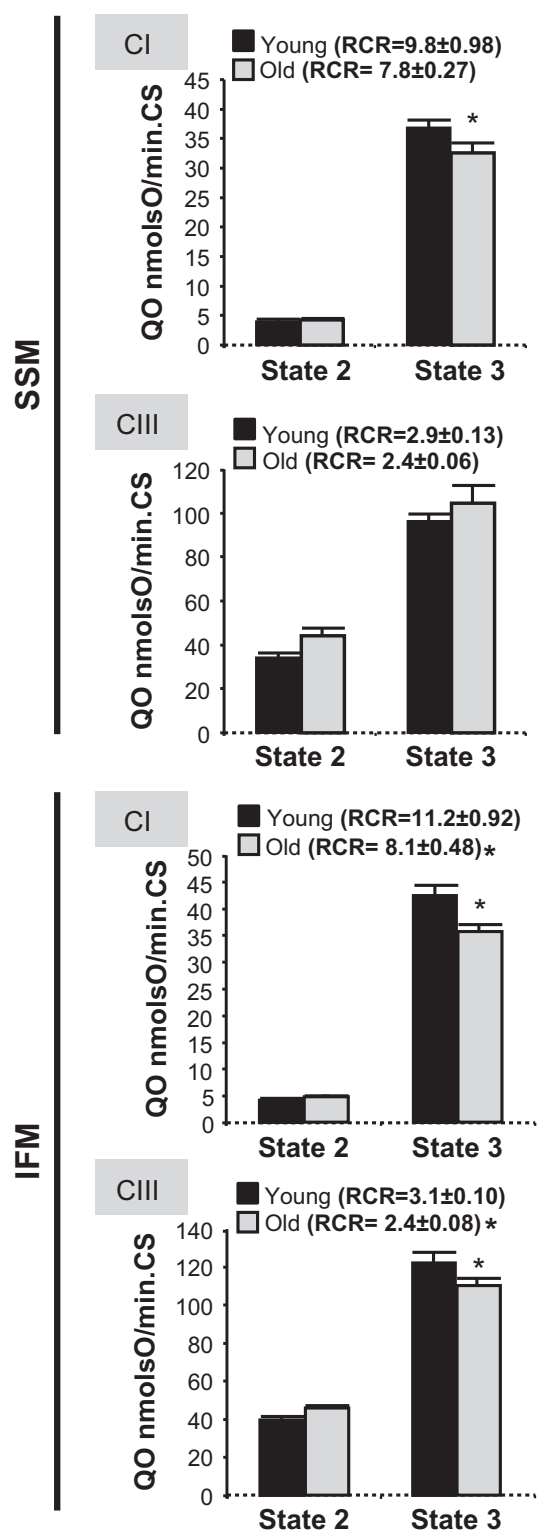
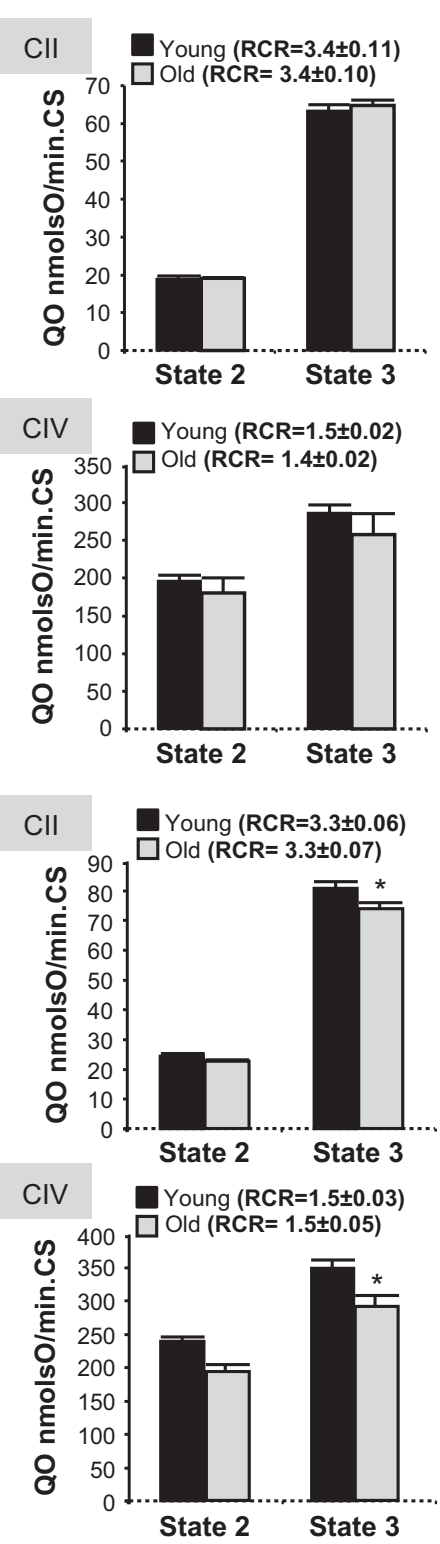

Figure 2 (a) ATP/PCr in intact hearts from young and old mice, quantified by NMR spectroscopy (left panel; $n=3$ hearts). Mitochondrial membrane potential (JC-1 ratio fluorescence) in intact cardiac myocytes from young and old mouse hearts under resting contidions and after induction of maximal mitochondrial depolarization with DNP (right panel). ( $n=14-26$ cardiomyocytes per group, five hearts). (b) Resting $\mathrm{O}_{2}$ consumption (state-2) and ADP-stimulated $\mathrm{O}_{2}$ consumption (state-3) in subsarcolemmal and interfibrillar mitochondria from young ( $<6$ months) and old ( $>20$ months) mouse hearts, mediated by substrates of complexes $1-4$, normalized by citrate synthase (CS) activity. $\mathrm{RCR}$, respiratory control rate for each respiratory complex (state-3/state-2). Mean \pm S.E.M. from $n=14-28$ replicates (5-10 hearts) 
oxidative damage in this protein. Consistently, proteins from mitochondria-associated membrane (MAM) fraction displayed a trend toward and increased oxidative state (Figure 6a). These data are compatible with the existance of an oxidized microenvironment around SR-mitochondria contact points, despite normal protein expression.

Increased oxidation of mitochondrial respiratory proteins in aged hearts. High-throughput quantitative proteomics followed by systems biology analysis indicated that there were no age-dependent changes in relative abundance of proteins of any of the five oxidative phosphorylation complexes in SSM or IFM (Figure $6 \mathrm{~b}$ and Supplementary Table 1). However, GELSILOX analysis revealed that aging was associated with an increased proportion of mitochondrial peptides containing oxidized Cys and a decrease in those containing reduced Cys in proteins of the Oxphos complexes (Figure 6c and Supplementary Table 2).

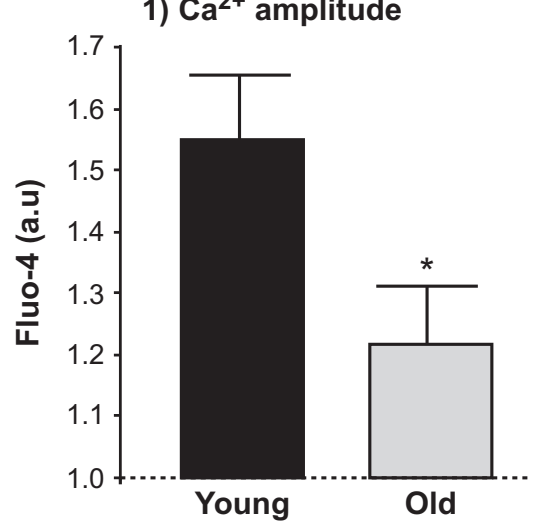

3) Rate of $\mathrm{Ca}^{2+}$ rise

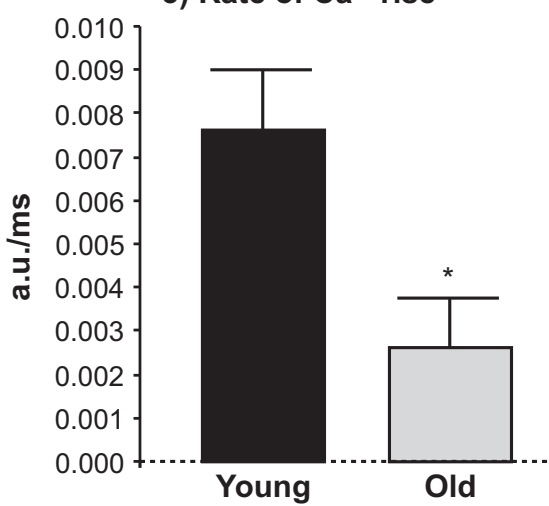

5) Rate of $50 \%$ decay

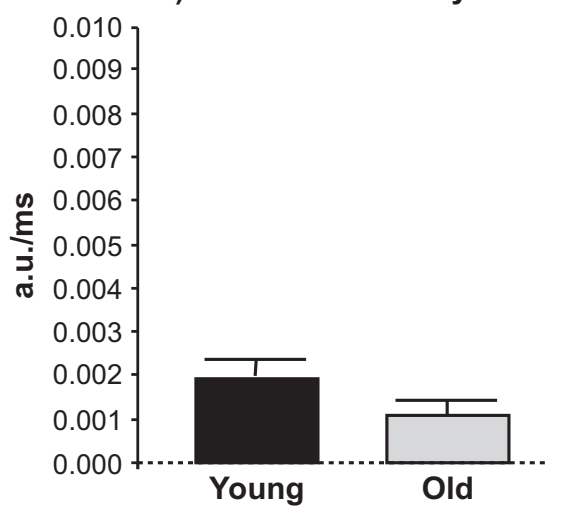

2) Time to $\mathrm{Ca}^{2+}$ peak

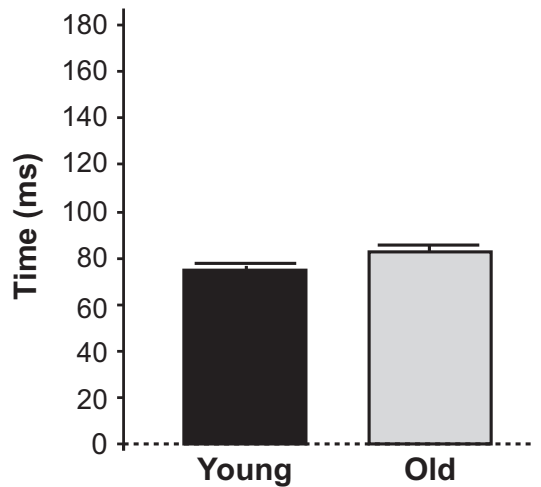

4) Time to $50 \%$ decay

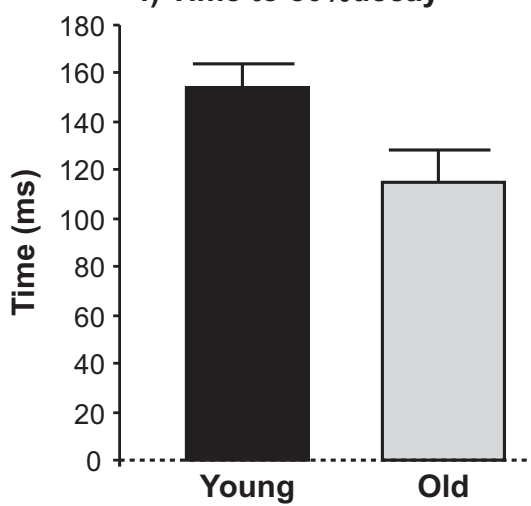

6) Total $\mathrm{Ca}^{2+}$ release

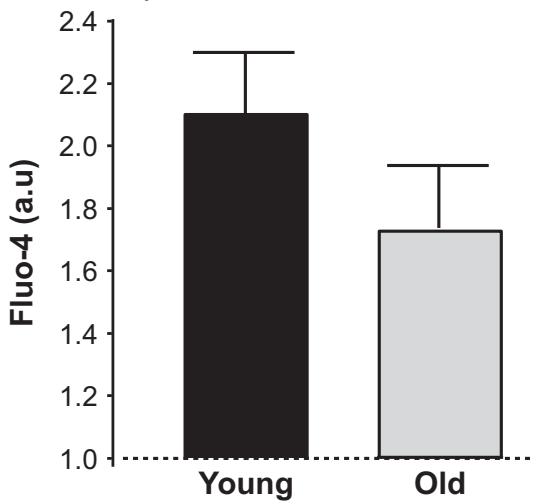

Figure 3 (a) Effect of aging on $\mathrm{Ca}^{2+}$ transient amplitude (panel-1), and SR Ca ${ }^{2+}$ release/uptake kinetics in field-stimulated (1 Hz) fluo-4 loaded cardiac myocytes from young and old mouse hearts (panels-2 to 5) and in total SR Ca ${ }^{2+}$ content after caffeine stimulation (panel-6). ${ }^{*}, P<0.05$ with respect to young, $n=9-12$ cardiomyocytes per group (six hearts). (b) Spontaneous spark frequency, amplitude, rate and diffusion in quiescent fluo-4 loaded cardiomyocytes from young and old mouse hearts. FWHM, full width at half maximum $(\mu \mathrm{m}) .{ }^{* *}, P<0.001$ with respect to young. Data represent mean \pm S.E.M. from 1600 sparks (34 cardiomyocytes, four hearts) 

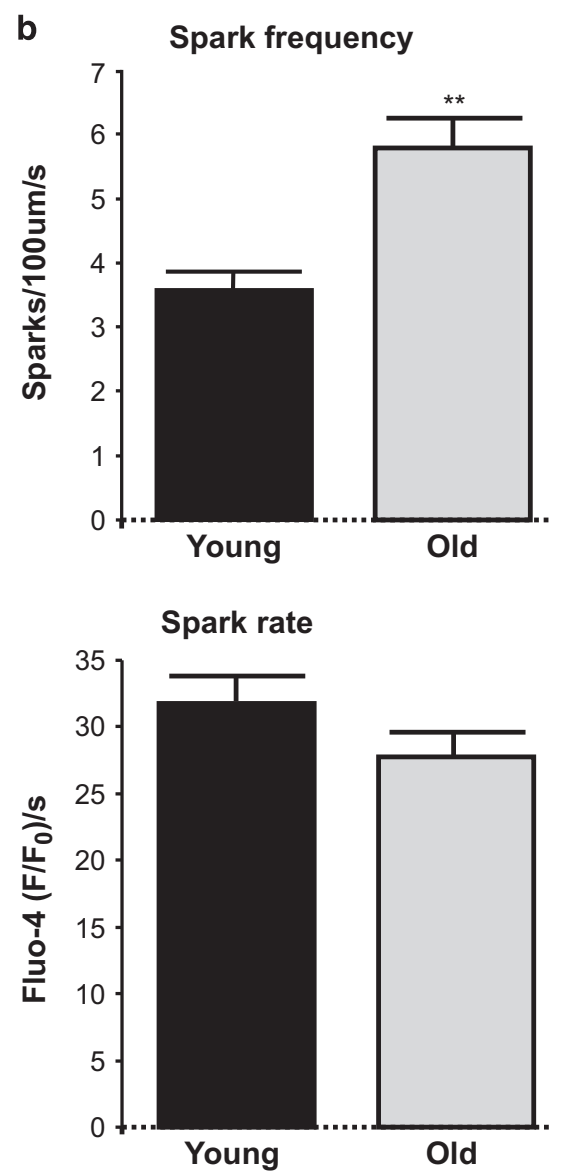

Figure 3 Continued

Disruption of SR-mitochondria connection in young cardiomyocytes mimicks age-induced alterations in calcium handling. Addition of $0.75 \mu \mathrm{mol} / \mathrm{l}$ colchicine to intact cardiomyocytes induced a partial disruption of SR-mitochondria interaction, confirmed by both decreased RyR-VDAC immunocolocalization and reduced number of amplification clusters in PLA assay (Figure 7a). The effect of this intervention was significantly less pronounced in cardiomyocytes of aged hearts. In cardiomyocytes from young mice, colchicine induced a parallel depression in the amplitude of $\mathrm{SR} \mathrm{Ca}^{2+}$ transients in intact cells and decreased mitochondrial $\mathrm{Ca}^{2+}$ uptake secondary to $\mathrm{SR} \mathrm{Ca}^{2+}$ transfer (caffeine) in permeabilized cells, but it had only little nonsignificant effect in cardiomyocytes from old mice (Figure 7b). These data indicate that partial pharmacological disruption of SRmitochondrial communication induces $\mathrm{Ca}^{2+}$ handling alterations that resemble those that are constitutively present in old cardiomyocytes. Nevertheless, colchicine did not have any effect on $\mathrm{Ca}^{2+}$ uptake kinetics or respiration efficiency in isolated mitochondria of any group of age (Figure 7c).

\section{Discussion}

The results of the present study indicate that SR-mitochondria communication is altered in aged cardiomyocytes, as manifested by reduced physical interaction among RyR and VDAC
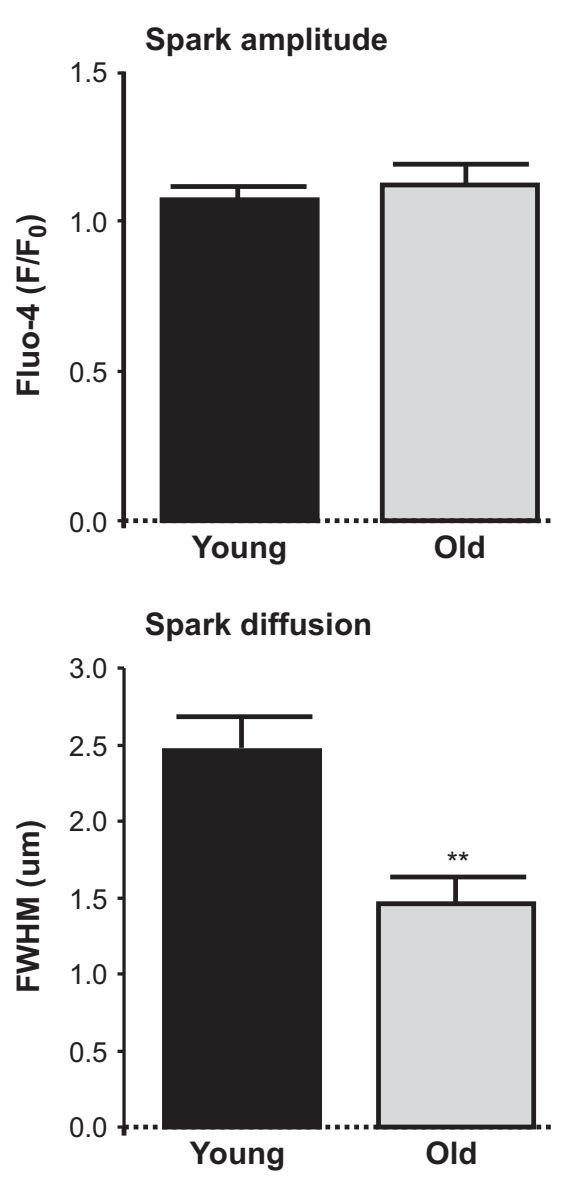

and depressed local $\mathrm{Ca}^{2+}$ transfer from SR to mitochondria, despite normal mitochondrial $\mathrm{Ca}^{2+}$ uniporter activity and SR $\mathrm{Ca}^{2+}$ content. As a consequence of reduced $\mathrm{Ca}^{2+}$ exchange, mitochondrial regeneration of the electron donor NADH and the antioxidant NADPH is depressed in old cardiomyocytes when exposed to increased frequency of pacing, reflecting an uncoupled bioenergetic feedback response, and mitochondrial ROS production is concomitantly increased under these conditions. IFM mitochondria - the population of mitochondria closely juxtaposed with $\mathrm{SR}$ - displayed reduced maximal $\mathrm{O}_{2}$ consumption and altered RCR. GSH levels are reduced in aging myocardium and differential redox proteomics using GELSILOX identified an age-dependent increase in Cys oxidation of mitochondrial VDAC and a trend toward an overall increase in the oxidative state of MAM proteins. This microenvironmental oxidation at the mitochondria-SR contact points was associated with abnormal RyR gating properties in SR from aged cardiomyocytes. These data identify a novel subcellular mechanism of functional decline during aging that could help to the development of cardioprotective strategies specifically addressed to the aged heart.

Disruption of SR-mitochondria spatial relationship during aging. In cardiac myocytes, SR is surrounded by a dynamic network of mitochondria extending along myofibril length. ${ }^{17}$ The positioning of mitochondria is supported by 
mitochondrial anchorage to cytoskeleton and SR through proteolysis-sensitive electron-dense tethering structures. ${ }^{18}$ Several molecular entities have been proposed to bridge the terminal cisternae of the SR or endoplasmic reticulum with mitochondria, as mitofusins 1 and $2,{ }^{15}$ the complex formed by RyR/IP3 and the outer mitochondrial membrane VDAC connected through the cytosolic chaperone $\operatorname{Grp} 75,{ }^{16}$ and other proteins related with apoptotic pathways, ${ }^{14}$ but their exact contribution to physical or chemical coupling or whether they may be redundant remains controversial. In cardiac cells, mitochondrial $\mathrm{Ca}^{2+}$ uptake secondary to SR $\mathrm{Ca}^{2+}$ release, essential for short and long-term metabolic adaptations, gives rise to locally restricted high calcium cell domains. ${ }^{9}$ To accomplish this, up to $90 \%$ of the $\mathrm{Ca}^{2+}$ release units of ventricular SR are close to mitochondria, with an estimated interorganelle surface distance of $37 \mathrm{~nm} .{ }^{19}$ Our results demonstrate a partially disrupted VDAC and RyR interaction in ventricular cardiomyocytes from aging hearts, determined by two independent techniques, immunocolocalization and PLA. Mander's coefficient analysis of SR and mitochondria immunolabelling indicates that, while most RyR fraction ( $>75 \%$ ) overlaps with mitochondrial VDAC in young cardiomyocytes, this interaction is reduced to $<60 \%$ in old cardiomyocytes. PLA, specifically addressed to detect those SR-mitochondria native clusters in which the spatial distance between RyR and VDAC is $\leqslant 40 \mathrm{~nm}$, confirmed the dissociating effect of age at this subcellar level.

Altered RyR-VDAC interaction in old hearts cannot be explained by a decrease in the expression of these proteins, because the amount of RyR and VDAC, as quantified by immunofluorescence labeling, western blot and proteomics, was similar in both groups of ages. The expression of other proteins potentially involved in SR-mitochondria bridging, like mitofusin-2 and the cytosolic chaperone Grp75, also remained preserved in old hearts at the different subcellular fractions. Because mitochondria are the major producers of superoxide, it is reasonable to expect that sustained mitochondrial ROS production derived from respiratory activity locally impacts on redox-sensitive proteins at the subcellular microdomain. Indeed, our experiments show increased mitochondrial ROS production in aging cardiomyocytes submitted to increased contractile activity and redox microdomains have been described at the interface between SR and mitochondria, in which NADPH oxidases contribute to ROS generation. ${ }^{20}$ Our proteomics data point to an increased overall oxidation of the MAM fraction, the subcellular proteinaceous SR-mitochondria tethering structure involved in intracellular $\mathrm{Ca}^{2+}$ signaling and bioenergetics regulation, ${ }^{21}$ as well as an increased oxidation of mitochondrial VDAC. However, the efficiency of our proteomics approach to specifically obtain Cys-containing peptides within RyR molecules is too low to get a reliable quantification of their redox state, probably due to the deep localization of the thiol sites in the receptor. RyR channels contain multiple, potentially redox-sensitive cysteine residues, and cysteine thiol oxidation appears to increase RyR channel activity. ${ }^{22}$ Our functional data on SR $\mathrm{Ca}^{2+}$ handling are fully consistent with an oxidation-induced alteration of the RyR gating properties, manifested by a substantial increase in spontaneous $\mathrm{Ca}^{2+}$ spark frequency and altered morphology (reduced $\mathrm{Ca}^{2+}$ diffusion pattern) and decreased $\mathrm{Ca}^{2+}$ transient amplitude in the aged cardiomyocytes, despite no significant alteration in total SR $\mathrm{Ca}^{2+}$ content. These SR $\mathrm{Ca}^{2+}$ abnormalities have been attributed to increased frequency of RyR opening events of less unitary duration and have been described in oxidative environments like those present in failing and aging hearts. ${ }^{5,23,24}$ It remains to be elucidated what type of conformational changes may occur in RyR proteins exposed to oxidative stress and how these changes may potentially modify their interaction with other proteins.

\section{Defective SR-mitochondria communication impacts on} local calcium handling. Our experiments demonstrate that old cardiomyocytes exhibit a depressed mitochondrial $\mathrm{Ca}^{2+}$ uptake that is secondary to reduced $\mathrm{Ca}^{2+}$ transfer from SR. This concept is supported by several observations: (1) it is specifically manifested in response to RyR stimulation with caffeine; (2) it takes place in digitonin-permeabilized cardiomyocytes, in which the contribution of sarcolemma and cytosol to mitochondrial $\mathrm{Ca}^{2+}$ handling is absent; (3) mitochondrial $\mathrm{Ca}^{2+}$ uptake is strictly normal when exposing isolated mitochondria to external $\mathrm{Ca}^{2+}$ in vitro. Our data also indicate that reduced $\mathrm{SR} \mathrm{Ca}^{2+}$ transfer in aged cardiomyocytes results in defective $\mathrm{NAD}(\mathrm{P}) \mathrm{H}$ regeneration when cells are submitted to increased contractile activity (high-rate pacing), indicating an altered bioenergetic feedback response. Moreover, impaired mitochondrial $\mathrm{Ca}^{2+}$ uptake in aged cardiomyocytes can be reproduced in young cells after pharmacological disruption of SR-mitochondrial physical interaction with colchicine. Of note, this disrupting maneuvre does not have any effect on mitochondrial $\mathrm{Ca}^{2+}$ uniporter activity or $\mathrm{O}_{2}$ consumption, which could reduce mitochondrial $\mathrm{Ca}^{2+}$ uptake by mechanisms independent of interorganelle communication.

An increasing number of evidences support the view that the coordination between mitochondrial ATP supply and mechanical activity demand is highly dependent on an efficient $\mathrm{Ca}^{2+}$ transfer from SR to mitochondria, ${ }^{15,25}$ and that altered SR-mitochondria $\mathrm{Ca}^{2+}$ exchange may underlie the pathophysiology of several cardiac diseases. ${ }^{26}$ In an acute setting, like the first phase of myocardial reperfusion, rapid and cyclic SR-induced $\mathrm{Ca}^{2+}$ oscillations - in a hyperoxidative cellular milieu - trigger mitochondrial permeabilization, hypercontracture and cell death. ${ }^{27,28}$ In this context, genetic or pharmacological inhibition of SR-mitochondria $\mathrm{Ca}^{2+}$ transfer have been demonstrated to have beneficial effects on cell survival. ${ }^{29}$ By contrast, chronically insufficient mitochondrial $\mathrm{Ca}^{2+}$ uptake due to defective SR-mitochondrial spatial organization contributes to oxidative stress and energy deficiency. ${ }^{15}$ This is because $\mathrm{Ca}^{2+}$ released by $\mathrm{RyR}$ is partially transferred to adjacent mitochondria, where it activates $\mathrm{Ca}^{2+}$-sensitive Krebs dehydrogenases and other downstream enzymes involved in energy production, like F1-F0 ATPase and adenine nucleotide translocase, as well as antioxidant pool regeneration. ${ }^{30-32}$ Therefore, ablation of mitofusin- 2 not only disrupts SR-mitochondrial cytoarchitecture but has been demonstrated to alter $\mathrm{Ca}^{2+}$ transients and mitochondrial $\mathrm{Ca}^{2+}$ uptake and to induce bioenergetic-redox mismatch in cardiac myocytes submitted to $\beta$-adrenergic stimulation. ${ }^{15}$ In a recent three-dimensional integrated cardiomyocyte computational model, ${ }^{33}$ increasing SR-mitochondria distance from 
$50 \mathrm{~nm}$ to $200 \mathrm{~nm}$ depressed mitochondrial $\mathrm{Ca}^{2+}$ uptake by $17 \%$ and $\mathrm{NADH}$ generation by $11 \%$ when pacing rates were switched from 0.5 to $2 \mathrm{~Hz}^{33}$ In our experiments, depressed
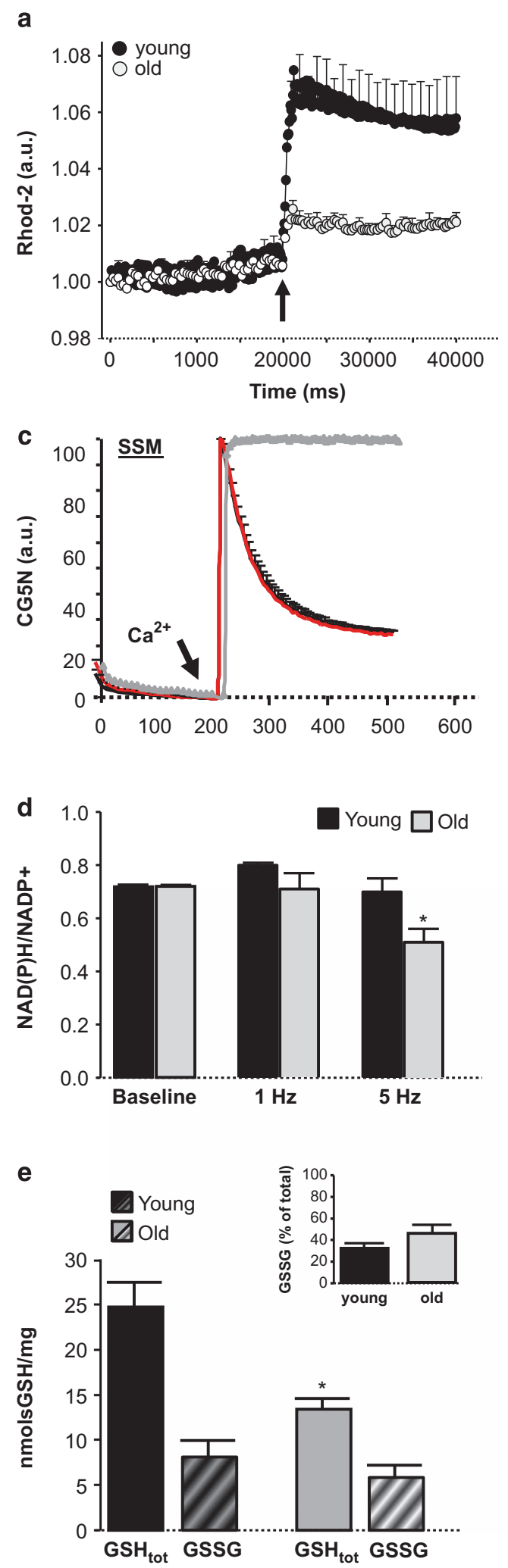

$\mathrm{NAD}(\mathrm{P}) \mathrm{H}$ regeneration in response to pacing stress occurred only in cardiomyocytes from aged hearts, indicating impaired bioenergetic feedback response secondary to inadequate
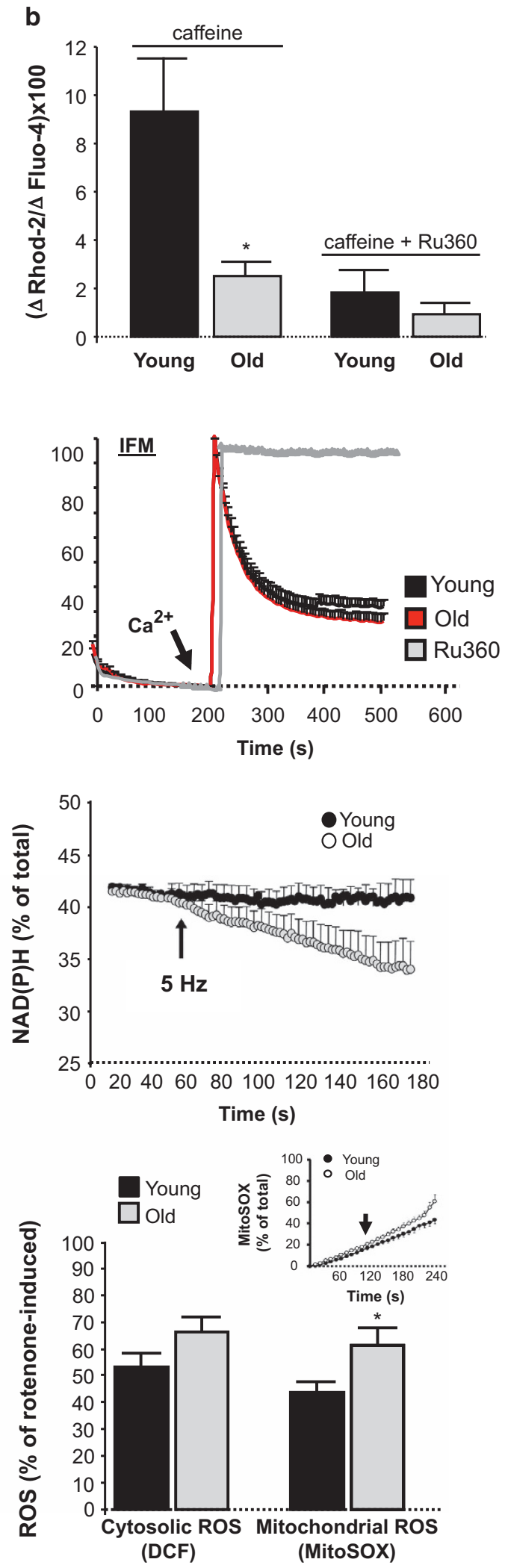
mitochondrial $\mathrm{Ca}^{2+}$ uptake, and was associated with increased ROS production at the mitochondrial compartment. This mechanism may aggravate the age-associated excess of toxic ROS in a vicious cycle. Importantly, the impact of aging on mitochondrial maximal $\mathrm{O}_{2}$ consumption capacity and RCR was specifically manifested in IFM. This finding is consistent with previous observations suggesting a greater susceptibility of IFM to aging ${ }^{34,35}$ and should be put in the context that this mitochondrial population represents the most important fraction of total cell mitochondria closely juxtaposed with SR, although other mitochondria may contact with RyR2. ${ }^{36}$ Remarkably, resting $\mathrm{O}_{2}$ consumption, ATP/PCr and $\Delta \psi_{\mathrm{m}}$ are preserved in old hearts, indicating that age-dependent mitochondrial energy deficiency develops only under stressful conditions (ADP-induced maximal $\mathrm{O}_{2}$ consumption and increased contractile activity) and involves the mitochondrial bioenergetics feedback response (NADPH regeneration and $\mathrm{RCR}$ ). This bioenergetic inefficiency cannot be attributed to reduced mitochondrial mass, which seems to remain preserverd in aging mouse cardiomyocytes as quantified by specific staining with Mitotracker red, total cardiac mitochondrial yield quantification and CS activity measurement.

Aging is characterized by augmented entropy, in which random and stochastic episodes not genetically controlled result in biologically defective molecules. Some covalent modifications - that is, oxidation, glycosilation, phosphorylation, conformational changes and genomic mutations eventually exceed cell repair capability. ${ }^{37}$ An insidious increase in the oxidation status has been consistently observed during senescence.,4 Our data confirm that mitochondrial respiratory complexes are overoxidized in the aged cardiomyocytes. This post-translational damage can reflect excessive ROS generation, decreased antioxidant capacity or reduced degradation of oxidized proteins. Recent evidences have suggested the defective mitochondrial $\mathrm{Ca}^{2+}$ uptake is one of the mechanisms involved in impaired antioxidant regeneration in failing cardiomyocytes. ${ }^{11,38}$

In conclusion, we propose a pathophysiological mechanism summarized in Figure 8, in which mitochondrial ROS derived from oxidative phosphorylation locally impacts on different protein targets, including electron transport chain and bridging proteins of the interorganelle space. Oxidative damage does not have significant consequences on mitochondrial energy production in old hearts under resting conditions but eventually disrupts the intimate connection between mitochondria and SR. The resulting alteration in RyR gating properties and $\mathrm{SR} \mathrm{Ca}^{2+}$ handling may, however, amplify cell damage in a positive feedback, as deficient $\mathrm{Ca}^{2+}$ transfer from RyR to adjacent mitochondria further increases oxidative damage (impairing NADPH regeneration) and ultimately leads to inefficient energy production.

\section{Materials and Methods}

Young adult (5-6 months) and old ( $>20$ months) C57BL/6 mice were used for in situ functional analysis (echochardiography) and for the obtention of myocardial tissue, isolated cardiomyocytes and mitochondria. Animal handling was approved by Research Commission on Ethics of the Hospital Vall d'Hebron. All procedures conformed to EU Directive 2010/63EU and Recommendation 2007/526/EC regarding the protection of animals used for experimental and other scientific purposes, enforced in Spanish law under Real Decreto 1201/2005.

Transthoracic Echocardiographic Analysis. Echocardiographic measurements were performerd in young and old mice under light anesthesia (isofluorane $0.5-1 \%$ ) with a Vivid-Q portable ultrasound system using a ILS $12 \mathrm{MHz}$ transducer (GE Healthcare, Wauwatosa, WI, USA). Conventional parameters (ejection fraction of the left ventricle (LVEF), left ventricular end-diastolic diameter (LVEDD), left ventricular end-systolic diameter (LVESD), septum wall thickness (SWT) and posterior wall thickness (PWT)) were measured in M-mode recordings at the level of the papillary muscles. Left ventricular fractional shortening was calculated as ((LVEDD-LVESD)/LVEDD) $\times 100$. Left ventricular mass was calculated as $0.8 \times\left(1.04 \times(\text { LVEDD+ PWT+SWT })^{3}-(\text { LVEDD })^{3}\right)+0.6$.

NMR spectroscopy. Myocardial energetic status was evaluated in Langendorf-perfused intact mouse hearts by NMR spectroscopy. ATP/PCr was measured as described. ${ }^{39}$ Spectra were acquired in a $9.4 \mathrm{~T}$ vertical magnet interfaced to a Bruker AVANCE 400 spectrometer (Billerica, MA, USA) tuned to $161.97 \mathrm{MHz}$; each spectra consisted in the accumulation of 400 scans and lasted $14 \mathrm{~min}$. The areas of Pcr and $\gamma$-ATP peaks were measured by deconvolution.

Isolation of heart mitochondria. SSM and IFM cardiac mitochondria were isolated by differential centrifugation from mouse hearts as originally described by Palmer et al. ${ }^{40}$ Ventricular tissue was minced in cold 'buffer A', containing (in mmo//): 290 sucrose, 5 MOPS at pH 7.4, 2 EGTA and 0.2\% deffated albumin. Minced tissue was mildly homogenized using a Potter-Elvehjem device. Homogenates were centrifuged at $750 \times g$ for $5 \mathrm{~min}$. Pellets and supernatants were processed independently to isolate different mitochondrial pools. For SSM mitochondria fraction, supernatants were centrifuged at $5000 \times g$ for $5 \mathrm{~min}$. For IFM fraction, the resulting pellets were resuspended in cold 'buffer B', containing (in $\mathrm{mmol} / \mathrm{l}): 100 \mathrm{KCl}, 5 \mathrm{MOPS}$ at $\mathrm{pH} 7.4,2 \mathrm{EGTA}$ and $0.2 \%$ deffated albumin with proteinase K (P2308, Sigma, Munich, Germany) at $2 \mathrm{mg} / \mathrm{g}$ wet weight, and quickly homogenized. Homogenates were centrifuged at $750 \times g$ for $5 \mathrm{~min}$. Supernatants were subjected to a subsequent centrifugation at $5000 \times g$ for 5 min to obtain IFM. Protein was determined by Bradford assay. For western blot analysis, SSM and IFM were additionally centrifugated using percoll buffer to increase the purity of preparations. Protein was determined by Bradford assay.

\section{Studies in isolated mitochondria}

Respiration assay. $\mathrm{O}_{2}$ consumption was quantified in SSM and IFM from young and old mice hearts incubated in respiration buffer (in mmol/l: $100 \mathrm{KCl}, 5 \mathrm{MOPS} \mathrm{pH}$

\footnotetext{
Figure 4 (a) Mitochondrial $\mathrm{Ca}^{2+}$ uptake throughout time in response to $\mathrm{SR} \mathrm{Ca}^{2+}$ release $(10 \mathrm{mmol} / \mathrm{l}$ caffeine, arrow) in digitonin-permeabilized rhod-2 loaded cardiac myocytes from old and young mouse hearts. $N=8-11$ cardiomyocytes per group $\left(n=5\right.$ hearts). (b) Maximal mitochondrial $\mathrm{Ca}^{2+}$ uptake (rhod-2) normalized by maximal SR Ca ${ }^{2+}$ release (fluo-4) in young and old permeabilized mouse cardiomyocytes. Addition of $10 \mu \mathrm{mol} / / \mathrm{Ru} 360$ (a specific blocker of the mitochondrial $\mathrm{Ca}^{2+}$ uniporter) prevented caffeineinduced mitochondrial $\mathrm{Ca}^{2+}$ uptake in both groups of ages. ${ }^{*}, P<0.05$ with respect to young. $n=7-11$ cardiomyocytes per group (five hearts). (c) Absence of age-dependent differences in the in vitro mitochondrial $\mathrm{Ca}^{2+}$ uptake kinetics (CG5N fluorescence), when exposing isolated subsarcolemmal (SSM) and interfibrillar (IFM) cardiac mitochondria to an external $\mathrm{Ca}^{2+}$ pulse of $30 \mu \mathrm{mol} / /$ (arrow). Addition of $10 \mu \mathrm{mol} / / \mathrm{Ru} 360$ prevented mitochondrial $\mathrm{Ca}^{2+}$ uptake. Mean $\pm \mathrm{S}$.E.M. of four replicates per group (six hearts). (d) NAD $(\mathrm{P}) \mathrm{H} / \mathrm{NAD}(\mathrm{P})+$ ratio $2 \mathrm{~min}$ after electrical stimulation at $1 \mathrm{~Hz}$ and $5 \mathrm{~Hz}$ to induce high contractile activity in intact cardiomyocytes from young and old mouse hearts (left panel), and kinetics of the NAD(P)H consumption in its reduced form, expressed with respect to total cell NADPH, during $5 \mathrm{~Hz}$ stimulation (right panel). Data represent mean \pm S.E.M. (10-19 cardiomyocytes per group, nine hearts). (e) Left panel: total glutathione (GSHtot) and oxidized glutathione levels (GSSG) in myocardial tissue of young and old mice. The inset shows the fraction of oxidized glutathione with respect to total one; Right panel: cytosolic and mitochondrial ROS production 2 min after electrical stimulation at $5 \mathrm{~Hz}$ to induce high contractile activity in intact cardiomyoctes from young and old mouse hearts, as quantified by DCF and MitoSox fluorescence. The inset shows the kinetics of short-term mitochondrial ROS production during pacing (arrow points the onset of $5 \mathrm{~Hz}$ stimulation)
} 
7.4, $2 \mathrm{EGTA}, 5 \mathrm{KH}_{2} \mathrm{PO}_{4}, 1 \mathrm{MgCl}_{2}, 0.1 \%$ deffated albumin) using Clark-type oxygen electrodes (Hansatech, Norfolk, UK) after the addition of specific substrates for each of the respiratory complexes (complex $1: 2 \mathrm{mmol} / / \mathrm{malate}+5 \mathrm{mmol} / \mathrm{l}$ glutamate;

a
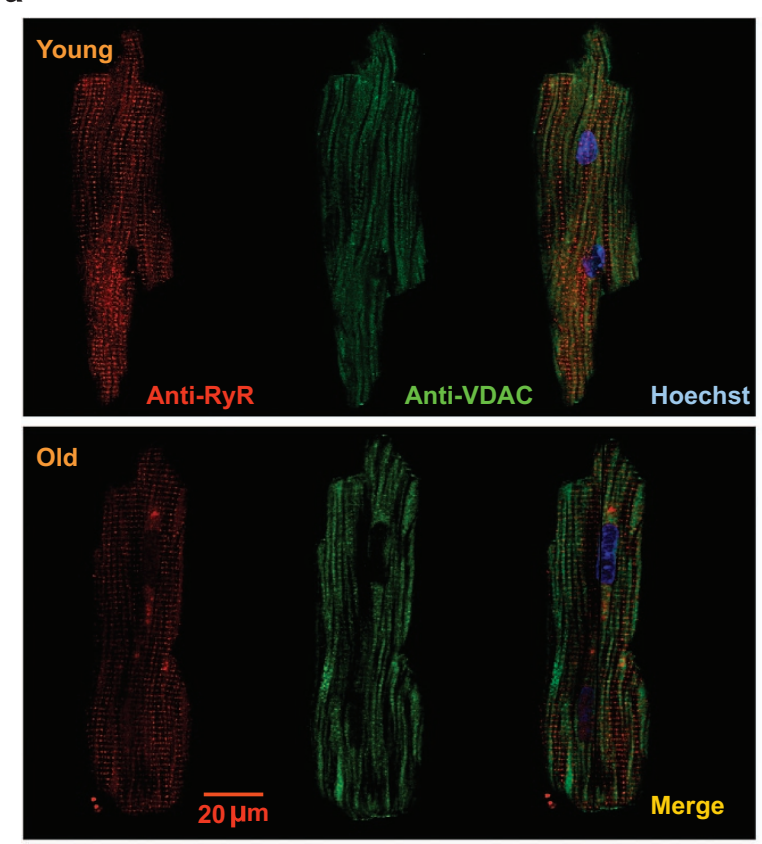

b
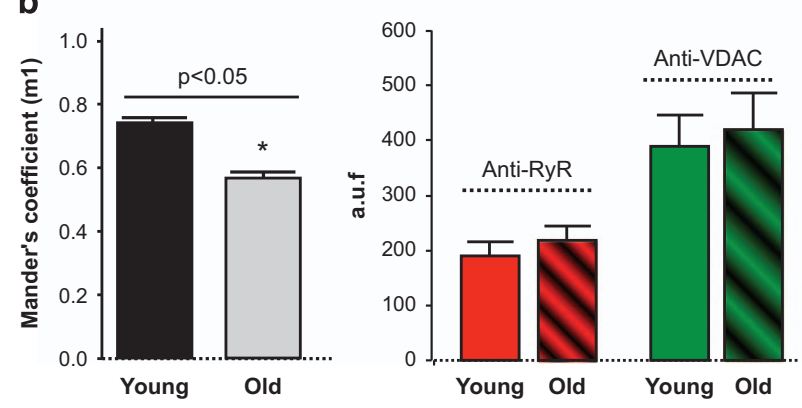

$\mathbf{e}_{1}$

Total homogenate

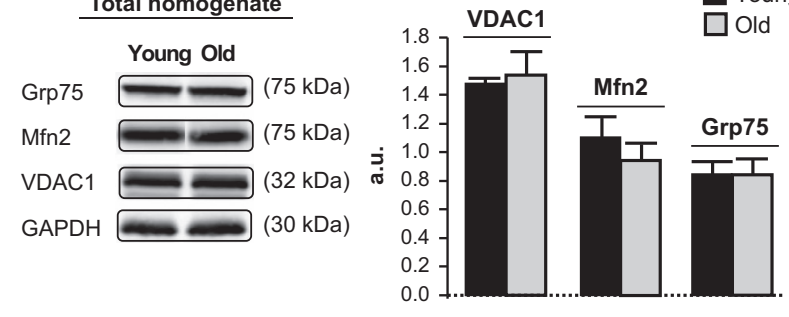

$\mathbf{e}_{3}$

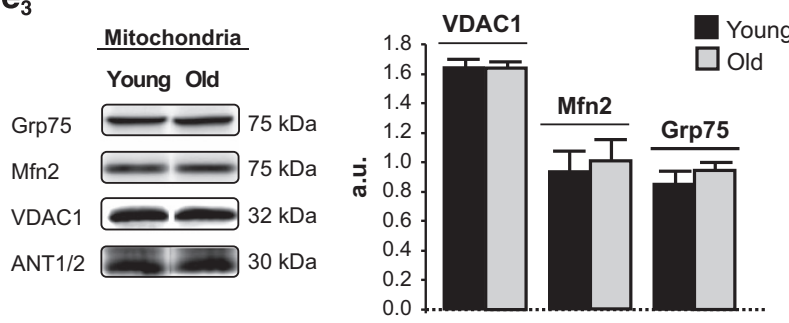

complex 2: $6 \mathrm{mmol} / /$ succinate with $0.5 \mu \mathrm{mol} / /$ rotenone to inhibit complex 1 ; complex 3: reduced form of 2,3 dimethoxy-5-methyl-1,4-benzoquinone; complex 4: ascorbate+NNN' $\mathrm{N}^{\prime}$ tetramethyl-p-phenylenediamine (TMPD)). Maximal $\mathrm{O}_{2}$ consumption

C
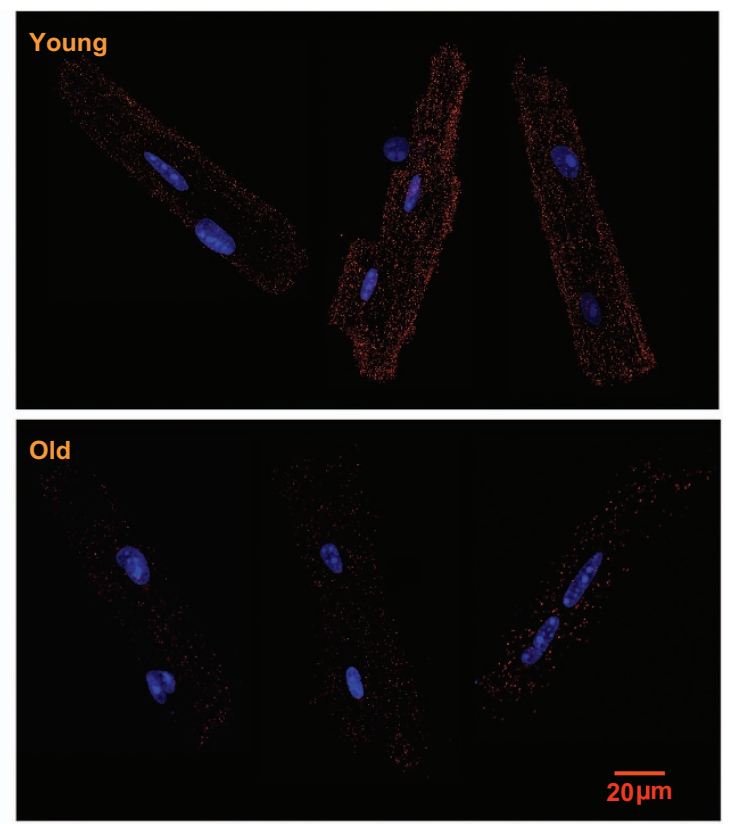

d
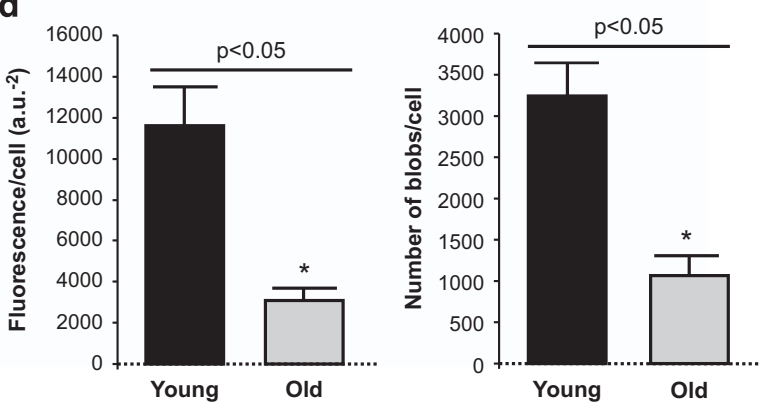

$\mathbf{e}_{2}$

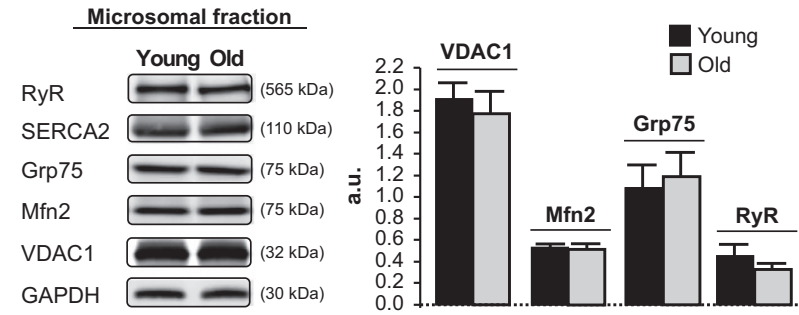


a

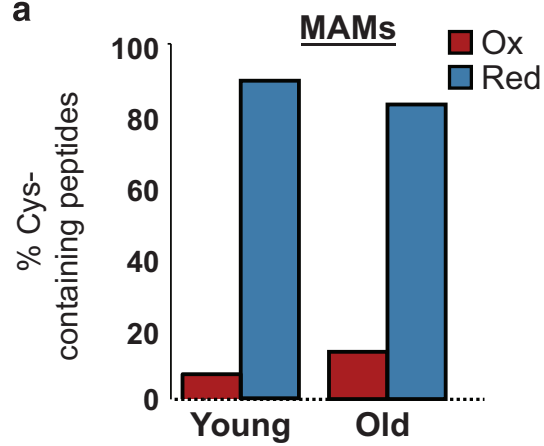

\begin{tabular}{|lrrrrrr|}
\hline & \multicolumn{2}{c}{ Ox } & & \multicolumn{2}{c|}{ Red } \\
\cline { 2 - 3 } VDAC1 & SSM & IFM & & SSM & IFM \\
YQVDPDACFSAC & -3.3 & -5.4 & & 4.19 & 2.68 \\
VDAC2 & & & & & \\
WNTDNTLGTEIAIEDQICQGLK & -2.5 & 2.63 & 4.95 \\
WCEYGLTFTEK & & 0.1 & 7.8 & 4.75 \\
\hline
\end{tabular}

b
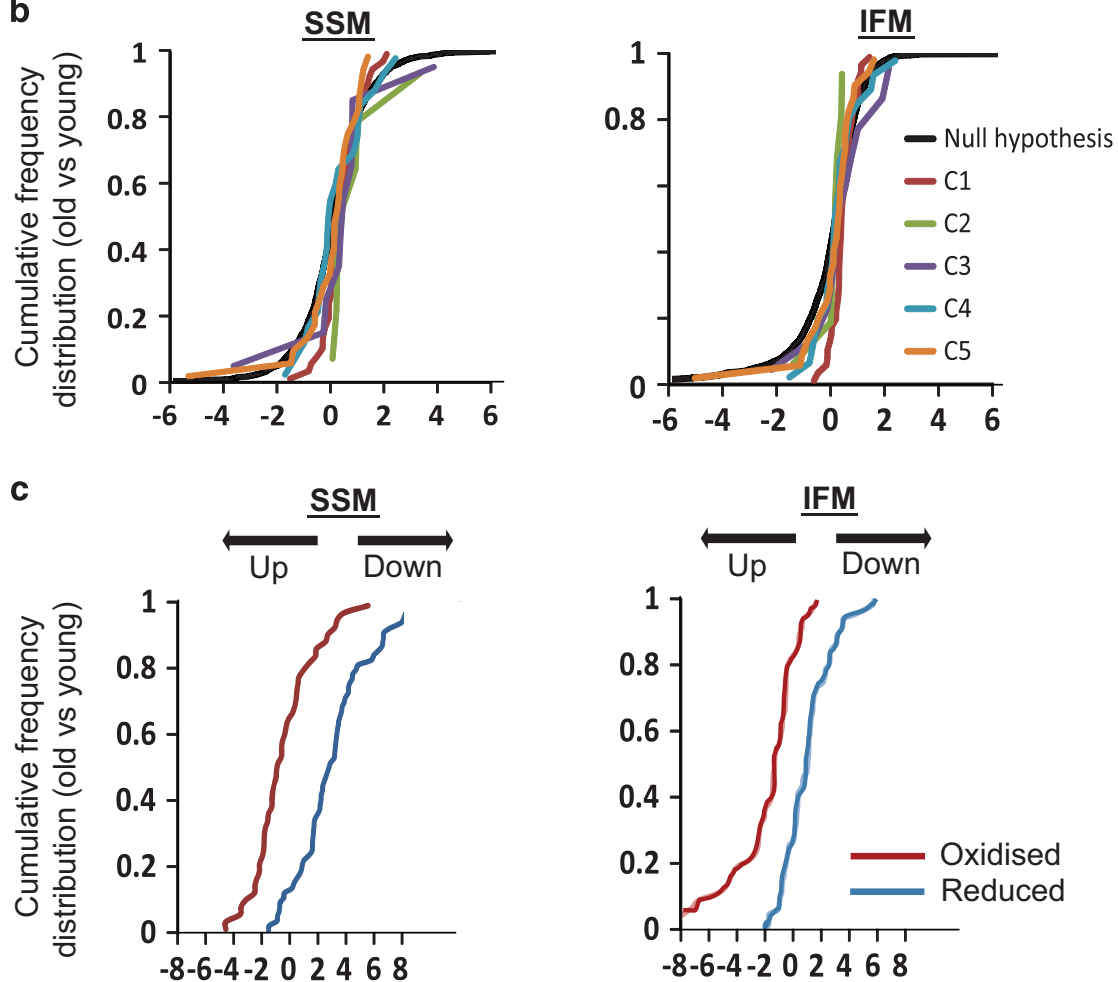

Figure 6 Effect of aging on: (a) quantitative redox proteomics using GELSILOX of proteins from mitochondria-associated membranes (MAMs; left) and of the Cys-containing peptides detected in mitochondrial VDAC proteins (right). The left graph represents the percentage of Cys-containing peptides identified in oxidized (red) or reduced (blue) forms. The numbers in the right table represent the standardized variable at the peptide level as in $\mathbf{b}$; negative values indicate an increase (in green) and positive values a decrease (in red) in the peptides containing Cys in oxidized form (Ox) or in reduced form (Red) in mitochondrial VDAC proteins in hearts from old mice. (b) The abundance of mitochondrial respiratory complexes (1-5) in subsarcolemmal (SSM) and interfibrillar (IFM) mitochondria. Data are shown as cumulative distributions of the standardized variable at the protein level (i.e., corrected log2 ratios of proteins expressed in units of standard deviation) for all oxidative phosphorylation proteins. The black sigmoid is the theoretical null hypothesis distribution; a displacement toward the left indicates an increase in protein concentration. All the categories follow very closely the null hypothesis distribution, indicating that aging does not affect the abundance of mitochondrial respiratory proteins. (c) Alterations in the abundance of oxidized (red) and reduced (blue) Cys-containing peptides in SSM and IFM from young and old mice hearts. Peptides containing Cys residues in different oxidation states were quantified using the GELSILOX method. The sigmoid curves represent the cumulative distribution of the standardized variable at the peptide level (i.e. corrected log2-ratios of peptides expressed in units of S.D.), for all peptides containing either oxidized or reduced Cys sites that belong to proteins from OxPhos complexes

Figure 5 (a) Confocal fluorescent images of young and old mouse cardiomyocyte simultaneously labeled with anti-RyR (red), anti-VDAC (green) and Hoechst (blue) for visualization of SR, mitochondria and nuclei, respectively. (b) Effect of aging on RyR-VDAC spatial interaction, as quantified by Mander's coefficient ( $\mathrm{m} 1$ ) analysis, expressed as the percentage of RyR - with respect to total RyR fluorescence - that overlaps with VDAC (left panel); in the right panel, total RyR and VDAC fluorescence. Mean \pm S.E.M. from 4 to 6 cardiomyocytes per group (four hearts). (c) Confocal fluorescent images of the RyR-VDAC interaction in different individual cardiomyocytes isolated from young and old mouse hearts, detected by proximity ligation assay (PLA). Positive cross-reactivity - reflecting an intermolecular distance of $<40 \mathrm{~nm}-$ is shown in red, nuclei are depicted in blue (Hoechst). (d) Aging was associated with a significant reduction in cell fluorescence resulting from RyR-VDAC cross-reactivity (left panel) and in the number of amplification spots (right panel), as quantified by PLA assay. Mean \pm S.E.M. of 1071-3250 blobs per group (15 cardiomyocytes, two hearts). (e) Western blot representative bands and quantification of the expression of proteins involved in SR and mitochondria $\mathrm{Ca}^{2+}$ transport and interorganelle communication in whole-heart homogenate, microsomal and mitochondrial fractions from young and old mice. Each protein of interest was normalized by the corresponding protein of reference as follows: in total homogenates, VDAC1/Grp75, Mfn2/GAPDH and Grp75/GAPDH; in microsomal fraction, Mfn2/VDAC1, VDAC1/Grp75, Grp75/GADPH and RyR/Grp75; in mitochondria, VDAC1/Grp75, Grp75/ANT1/2 and Mfn2/ANT1/2. Mean \pm S.E.M. of $n=8$ replicates from four hearts/group) 

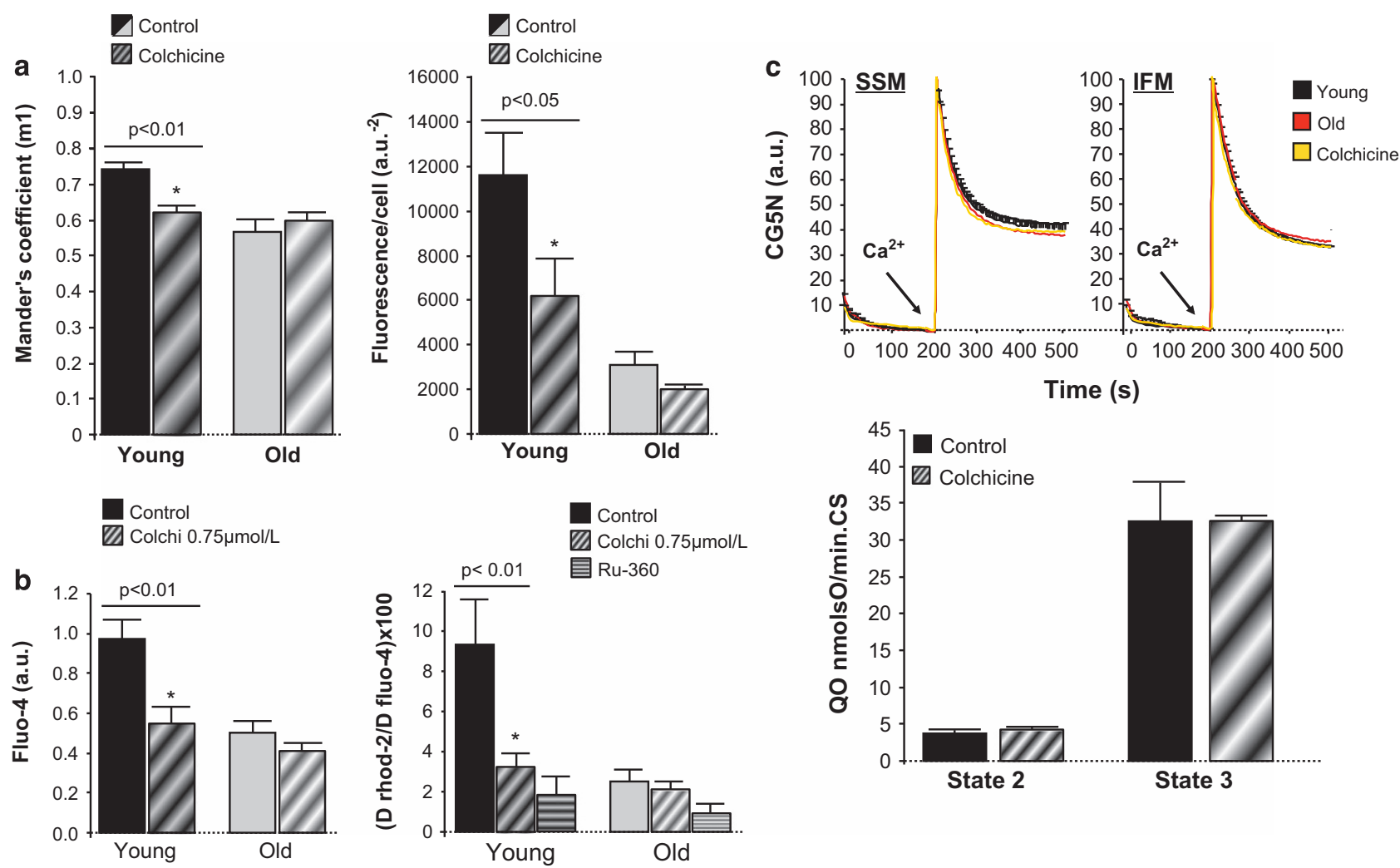

Figure 7 Effect of $0.75 \mu$ mol// colchicine on: (a) RyR-VDAC spatial interaction quantified by Mander's coefficient (m1) analysis, indicating a reduction of the percentage of RyR (with respect to total RyR) that overlaps with VDAC in young cardiac myocytes, without effect in old cardiomyoyctes (left panel); and RyR-VDAC positive cross-reactivity detected by proximity ligation assay (PLA; right panel; $n=4-6$ ). (b) The amplitude of $\mathrm{Ca}^{2+}$ transients in fluo-4 loaded cardiomyocytes submitted to field-stimulation (left panel), and mitochondrial $\mathrm{Ca}^{2+}$ uptake in response to SR $\mathrm{Ca}^{2+}$ release in digitonin-permeabilized cardiac myocytes (right panel). Ru360 $10 \mu$ mol/l was used to specifically inhibit mitochondrial $\mathrm{Ca}^{2+}$ uniporter ( $\left.n=6-11\right)$. (c) In vitro mitochondrial $\mathrm{Ca}^{2+}$ uptake (CG5N fluorescence) in isolated subsarcolemmal (SSM) and interfibrillar (IFM) mitochondria from young mouse hearts with or without colchicine (yellow and black), and from old mouse hearts (red), exposed to an external $30 \mu$ mol// Ca ${ }^{2+}$ pulse (arrow; top panels), complex 11 mediated $\mathrm{O}_{2}$ consumption (state-2) and ADP-stimulated $\mathrm{O}_{2}$ consumption (state-3) in SSM from young mouse hearts, normalized by citrate synthase activity, in the absence (control) or in the presence of colchicine (bottom panel). Mean \pm S.E.M. of four replicates per group (six hearts)

(state-3) was obtained with $0.25 \mathrm{mmol} / \mathrm{ADP}$. RCR was calculated as ADPstimulated $\mathrm{O}_{2}$ consumption (state-3)/non-stimulated $\mathrm{O}_{2}$ consumption (state-2). CS activity was determined by colorimetry and was used to normalize data on mitochondrial respiration. ${ }^{41}$

Mitochondrial calcium uptake: Mitochondrial $\mathrm{Ca}^{2+}$ uptake was fluorometrically quantified in $150 \mu \mathrm{g}$ of SSM or IFM incubated in $235 \mu \mathrm{l}$ of respiration buffer with $0.5 \mu \mathrm{mol} / /$ calcium green-5N (CG5N hexapotassium salt, Invitrogen, Madrid, Spain). Mitochondria were exposed to an external $\mathrm{Ca}^{2+}$ pulse of $30 \mu \mathrm{mol} / /$ in the presence of $1 \mu \mathrm{mol} / /$ cyclosporine $A$ to avoid membrane permeabilization. Changes in $530 \mathrm{~nm}$ fluorescence were recorded every $10 \mathrm{~s}$. Fluorescence decay after $\mathrm{Ca}^{2+}$ addition reflected the kinetics of mitochondrial $\mathrm{Ca}^{2+}$ uniporter and could be effectively inhibited by $10 \mu \mathrm{mol} / /$ of the specific blocker Ru360.

Isolation of mouse cardiac myocytes. For the obtention of cardiomyocytes, hearts from young ( $<6$ months) or old ( $>20$ months) mice were perfused in a Langendorff system (Trallero, Barcelona, Spain) for 15 min with a modified Krebs buffer (in mmol/l: $110 \mathrm{NaCl}, 2.6 \mathrm{KCl}, 1.2 \mathrm{KH}_{2} \mathrm{PO}_{4}, 1.2 \mathrm{MgSO}_{4}, 11$ glucose and 10 butanedione monoxime, $\mathrm{pH} 7.4$ ) with $0.03 \%$ type II collagenase (Serva, Heidelberg, Germany). Perfused tissue was subjected to differential centrifugation. Calcium tolerant rod-shaped cardiomyocytes were selected by sedimentation in $4 \%$ BSA (bovine serum albumin) gradient, and plated on laminin-coated cover slips. Only when the initial yield of rod-shaped cardiac myocytes was $>50 \%$, preparations were considered suitable for experiments.
Lysosome, mitochondria and lipofuscin staining. Lysosomes were visualized in cardiomyocytes loaded with $50 \mathrm{nmol} / /$ lysotracker green $\left(30 \mathrm{~min}, 37^{\circ} \mathrm{C}\right)$ and excited at $560 \mathrm{~nm}$ using an Ar/Kr laser confocal system (Yokogawa CSU10, Tokyo, Japan; Nipkow spinning disk), set on an Olympus IX70 (VoxCell Scan, Visitech, Sunderland, UK) with $\times 60$ oil immersion objective lens. Mitochondrial pool was estimated in confocal images of intact cells after labeling mitochondria with $1 \mu \mathrm{mol} / /$ MitoTracker Red CMXRos $\left(30 \mathrm{~min}, 37^{\circ} \mathrm{C}\right.$ ). Lipofuscin pigment was observed as autofluorescence after $488 \mathrm{~nm}$ laser excitation. In all cases, cell fluorescence was analyzed in background-substracted images using commercially available software (VoxCell Scan, Visitech).

Mitochondrial membrane potential $\left(\Delta \Psi_{\mathrm{m}}\right)$ in intact cardiomyocytes. Resting $\Delta \Psi \mathrm{m}$ was analyzed in isolated cardiomyocytes loaded with $10 \mu \mathrm{mo} / / \mathrm{IJC}-1\left(6 \mathrm{~min}, 37^{\circ} \mathrm{C}\right)$ and excited at $488 \mathrm{~nm}$ (Ar/Kr laser confocal system). Green $(520 \mathrm{~nm})$ and red $(590 \mathrm{~nm})$ emission lights were simultaneously recorded at $\times 60$ (CCD cameras, Hamamatsu City, Japan) and $590 / 520 \mathrm{~nm}$ fluorescence ratio was calculated as an index of $\Delta \Psi \mathrm{m}$ and expressed relative-to-maximal mitochondrial membrane depolarization achieved with $200 \mu \mathrm{mol} / /$ dinitrophenol (DNP).

Induction of SR-mitochondria calcium transfer in permeabilized cardiomyocytes. To analyze the fraction of mitochondrial $\mathrm{Ca}^{2+}$ uptake that is dependent on $\mathrm{SR} \mathrm{Ca}{ }^{2+}$ transfer without the contribution of sarcolemma/cytosol, cardiomyocytes were loaded with $5 \mu \mathrm{mol} / / \mathrm{rhod}-2$ using the cold-warm protocol $\left(60 \mathrm{~min}\right.$ at $4^{\circ} \mathrm{C}$ followed by $30 \mathrm{~min}$ at $37^{\circ} \mathrm{C}$ ) and the sarcolemma of the cells was subsequently permeabilized with $10 \mu \mathrm{mol} / /$ digitonin $\left(2 \mathrm{~min}, 37^{\circ} \mathrm{C}\right)$ in intracellularlike buffer (in mmol/l: $5 \mathrm{MgCl} 2,10$ HEPES, 250 sucrose, 25 Tris, 5 succinate, 

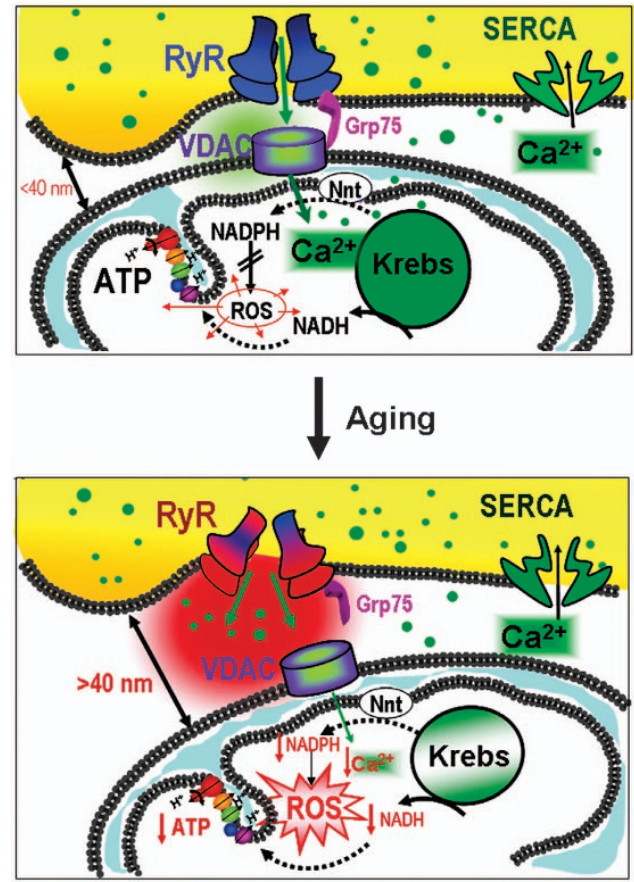

Figure 8 Schematic representation of the proposed mechanism by which aging induces SR-mitochondria disruption in cardiomyocytes

2 ATP, pH 7.2) under $\mathrm{Ca}^{2+}$ free conditions (2 mmol/l EGTA). SR Ca ${ }^{2+}$ release was induced with a pulse of caffeine $(10 \mathrm{mmol} / \mathrm{l})$ and mitochondrial $\mathrm{Ca}^{2+}$ uptake was monitored as changes in rhod-2 fluorescence throughout time with respect to the initial value (F/F0, Ex:561 nm/Em:605 nm) using an Ar/Kr laser confocal system (Yokogawa CSU10, Nipkow spinning disk), set on an Olympus IX70 (VoxCell Scan, Visitech) at $\times 60$.

Quantification of NAD(P)H regeneration. NAD $(P) H$ regeneration from $N A D(P)$ was determined in intact cardiomyocytes as autofluorescence after excitation at $340 \mathrm{~nm}(E m: 450 \mathrm{~nm})$ with the aid of a xenon lamp (Visitech monochromator, UK) on the stage of an inverted microscope (Olympus IX70, Tokyo, Japan), at $\times 40$. For calibration, maximal reduction state of $\mathrm{NAD}(\mathrm{P}) \mathrm{H}$ was achieved after the addition of $2 \mathrm{mmol} / \mathrm{l}$ sodium cyanide, and minimal reduction state was achieved after the addition of $200 \mu \mathrm{mol} / \mathrm{I}$ DNP. Results were expressed as the ratio of $\mathrm{NADH}(\mathrm{P}) \mathrm{H} / \mathrm{NAD}(\mathrm{P})+$ and as percentage of the reduced form with respect to total $\mathrm{NAD}(\mathrm{P}) \mathrm{H}$ pool according to the calibrated data. ${ }^{15}$ To test the effect of increasing contractile activity on $\mathrm{NAD}(\mathrm{P}) \mathrm{H}$ consumption/regeneration, electrical pacing of the cells was increased from $1 \mathrm{~Hz}$ to $5 \mathrm{~Hz}$.

Cytosolic and mitochondrial ROS production. ROS production in cytosolic and mitochondrial compartments was analyzed in freshly isolated cardiomyocytes simultaneously labeled with $10 \mu \mathrm{mol} / \mathrm{l}$ of the cytosolic ROSsensitive fluorochrome $2^{\prime}, 7^{\prime}$-dichlorodihydrofluorescein diacetate $\left(30 \mathrm{~min}, 37^{\circ} \mathrm{C}\right)$ and $5 \mu \mathrm{mol} / /$ of the mitochondrial ROS-sensitive fluorochrome MitosSOX red $\left(5 \mu \mathrm{mol} / /, 10 \mathrm{~min}, 37^{\circ} \mathrm{C}\right)$. Cells were electrically stimulated at low $(1 \mathrm{~Hz})$ and high frequencies $(5 \mathrm{~Hz})$. At the end of the protocol, $250 \mu \mathrm{mol} / /$ of the mitochondrial respiratory complex 1 inhibitor rotenone was added to induce a peak of ROS production. Fluorescence was recorded using an $\mathrm{Ar} / \mathrm{Kr}$ laser confocal system (Visitech, Ex: $488 \mathrm{~nm} / \mathrm{Em}: 520-580 \mathrm{~nm}$ ) on the stage of an inverted microscope (Olympus IX70). Results were expressed as relative changes with respect to peak ROS induced by rotenone. Image acquisition was set at 1 image/10 s to avoid phototoxicity.

\section{SR calcium handling}

$S R \mathrm{Ca}^{2+}$ transients in field-stimulated cardiomyocytes: Intact cardiomyocytes loaded with the cytosolic $\mathrm{Ca}^{2+}$ indicador fluo- $4\left(5 \mu \mathrm{mol} / /, 30 \mathrm{~min}\right.$ at $\left.37^{\circ} \mathrm{C}\right)$ were superfused with a control HEPES buffer ( $\mathrm{NaCl} 150 \mathrm{mmol} / \mathrm{l}, \mathrm{KCl} 5.4 \mathrm{mmol} / \mathrm{l}$, HEPES acid $10 \mathrm{mmol} / /, \mathrm{CaCl}_{2} 2 \mathrm{mmol} / /$, glucose $1 \mathrm{mmol} / /$, pyruvate $2.5 \mathrm{mmo} / /$, creatine $5 \mathrm{mmo} / /$, taurine $5 \mathrm{mmo} / /$, at $\mathrm{pH}=7.4$ ) and electrically stimulated at $1 \mathrm{~Hz}$ (biphasic pulse, SIU-102, Warner Instruments, Hamden, CT, USA). Fluorescence changes throughout time were recorded using an $\mathrm{Ar} / \mathrm{Kr}$ laser confocal system (Yokogawa CSU10, Nipkow spinning disk), set on an Olympus IX70 (VoxCell Scan, Visitech) at $\times 60$, and expressed as changes throughout time with respect to the initial value (F/F0; Ex:488 nm/Em:520 nm). Image acquisition was set at 40 images/ s. Data were analyzed with VoxCell Scan software (Visitech).

Spontaneous SR $\mathrm{Ca}^{2+}$ sparks: Spontaneous $\mathrm{SR} \mathrm{Ca}^{2+}$ sparks were analyzed in intact fluo-4 loaded cardiomyocytes incubated in control HEPES buffer using a spectral confocal microscope (Ex:488 nm, Olympus Spectral Confocal Microscopy FV1000, Olympus). Spark frequency (sparks $\left.\times\left(100 \mu \mathrm{m}^{-1}\right) \times\left(\mathrm{s}^{-1}\right)\right)$, amplitude $\left(\Delta \mathrm{F} / \mathrm{F}_{0}\right)$, rate $\left(\Delta \mathrm{F} / \mathrm{F}_{0} \times\left(\mathrm{s}^{-1}\right)\right)$ and morphology (full width at half-maximal amplitude, $\mu \mathrm{m})$ were quantified using Spark Master plugin of ImageJ software (NIH, Bethesda, $\mathrm{MD}, \mathrm{USA})$.

$S R \mathrm{Ca}^{2+}$ load: Total SR $\mathrm{Ca}^{2+}$ load was analyzed in intact cardiomyocytes loaded with the cytosolic $\mathrm{Ca}^{2+}$ indicator fluo-4 $\left(5 \mu \mathrm{mol} / /, 30 \mathrm{~min}\right.$ at $\left.37^{\circ} \mathrm{C}\right)$. Cells were submitted to a brief field-stimulation at $1 \mathrm{~Hz}$ for $30 \mathrm{~s}$ to allow $\mathrm{Ca}^{2+}$ transient stabilization followed by a single pulse of $10 \mathrm{mmol} / \mathrm{l}$ caffeine. Maximal amplitude of caffeine-induced peak fluorescence was normalized by the initial fluorescence value (F/FO) and considered as an index of total SR $\mathrm{Ca}^{2+}$ load.

\section{Spatial proximity between SR and mitochondria}

Immunolabeling and colocalization of RyR and VDAC: Isolated cardiomyocytes placed on laminin-coated coverslips were fixed (99.6\% acetone cooled at $\left.-20^{\circ} \mathrm{C}, 5 \mathrm{~min}\right)$, permeabilized $(0.025 \%$ Triton $\mathrm{X}-100$ in phosphatebuffered saline (PBS)) and incubated at $4{ }^{\circ} \mathrm{C}$ overnight with mouse monoclonal RyR antibody (34C Abcam, Cambridge, UK; $1: 50$ ) and rabbit polyclonal VDAC antibody (15895Abcam, $1: 50$ ) in PBS-BSA 1\%. This was followed by $1 \mathrm{~h}$ incubation at room temperature with secondary Alexa antimouse-561 and Alexa antirabbit-488. Nuclei were stained with $10 \mu \mathrm{g} / \mathrm{ml}$ Hoeschst-33342. Mounted samples were observed with a spectral confocal microscope (Olympus Spectral Confocal Microscopy FV1000, Olympus). Degree of RyR-VDAC overlap was quantified with Mander's coefficient analysis (JaCop, ImageJ software).

Proximity ligation assay. Isolated cardiomyocytes were simultaneously labeled with monoclonal RyR antibody (34C Abcam, 1:50) and rabbit polyclonal VDAC antibody (15895Abcam, 1:50), followed by the corresponding secondary antibodies (Alexa antimouse-561 and Alexa antirabbit-488) conjugated with the PLA oligonucleotide probes (PLA probe rabbit PLUS and PLA probe rat MINUS; Olink Bioscience, Uppsala, Sweden) for $1 \mathrm{~h}$ at $37^{\circ} \mathrm{C}$. For ligation and amplification reactions, Duolink InSitu detection kit recommendations were followed (Olink Bioscience). Cell images were registered with a spectral confocal microscope (FluoView-1000, Olympus). Positive fluorescent cross-reactivity was quantified in background-substracted images using BlobFinder software (Centre for Image Analysis, Uppsala University, Sweden).

Western blot. Mouse heart homogenates, microsomal, MAMs and mitochondria extracts were obtained by protein fractionation. Briefly, fresh cardiac mouse ventricles were minced and homogenized using a Potter-Elvehjem PTFE pestleglass tube at 1400 r.p.m. on ice-cold isolation buffer (HEPES acid $10 \mathrm{mmol} / /$, manitol $225 \mathrm{mmol} / /$, sucrose $75 \mathrm{mmol} / /$, EGTA $0.1 \mathrm{mmol} / /$ at $\mathrm{pH}=7.4$ ). After an initial centrifugation step $\left(750 \times g\right.$ for $\left.5 \mathrm{~min}, 4^{\circ} \mathrm{C}\right)$, nuclei and other cell debris were discarded in the pellet, and supernatant was centrifuged $(10000 \times g$ for $10 \mathrm{~min}$, at 4 $\left.{ }^{\circ} \mathrm{C}\right)$. The resulting pellet contained crude mitochondrial fraction. Supernatant was ultracentrifuged $\left(100000 \times \mathrm{g}\right.$ for $1 \mathrm{~h}$, at $\left.4^{\circ} \mathrm{C}\right)$ to obtain cytosolic fraction in the supernatant and microsomal vesicles in the pellet. Crude mitochondrial fraction previously obtained was purified in a $30 \%$ Percoll gradient column. Percoll gradient column was ultracentrifuged $\left(90000 \times \mathrm{g}\right.$, for $30 \mathrm{~min}$ at $\left.4{ }^{\circ} \mathrm{C}\right)$ in a swinging rotor, resulting in pure mitochondria (heavy fraction) and MAM (light fraction). ${ }^{42}$ Equal amounts of protein $(70 \mu \mathrm{g})$ supplemented with $1 \%$ SDS (Bio-Rad, Hercules, CA, USA; 161-0301) were subjected to PAGE. Samples were preheated ( $\left.95^{\circ} \mathrm{C}, 5 \mathrm{~min}\right)$ in SDS reducing buffer, separated on $6-12 \%$ acrylamide/bis (Bio-Rad) gels and transferred to Amersham Hybond-ECL nitrocellulose membranes (GE Healthcare). The membranes were blocked in TBS-T solution (Tris-buffered saline, $0.1 \%$ Tween20) with $5 \%$ non-fat milk powder. Proteins were detected with RyR (Abcam, 
ab2868), VDAC1 (Abcam, ab15895), GRP75 (SantaCruz Biotechnology Inc., Dallas, TX, USA; sc-13967), GAPDH (Gene Tex, San Antonio, TX, USA; GT239), Mitofusin-2 (Abcam, ab56889) and ANT1/2 (SantaCruz Biotechnology Inc., sc-9299) antibodies in TBS-T with $3 \%$ BSA (Sigma). Horseradish peroxidase-conjugated IgGs were used as secondary antibodies: antimouse (Sigma, A4416), antirabbit (Pierce, 31460), and anti-goat (Thermo Scientific, Waltham, MA, USA; 31402). Peroxidase reactions were carried out and visualized using Supersignal West Dura Extended Duration Substrate (Thermo Scientific) and the chemiluminescence imaging system LAS-3000 (Fujifilm, Tokyo, Japan). Band intensities were quantified with Science Lab-2001 Image Gauge (Fujjilm).

$\beta$-gal quantification in mouse hearts. $\beta$-gal was determined in heart extracts from young and old mice using the soluble $\beta$-galactosidase method. ${ }^{43}$ Frozen tissue $(0.1-0.2 \mathrm{~g})$ was homogenized in $0.1 \mathrm{~mol} / \mathrm{l}$ citrate $(\mathrm{pH} 4.5)$ and centrifuged at $12000 \times \mathrm{g}$ for $7 \mathrm{~min}$. The supernatants were diluted in citrate assay buffer containing 2-nitrophenyl- $\beta$-D-galactopyranoside $(2 \mathrm{mg} / \mathrm{ml})$ and $1 \mathrm{mmol} / \mathrm{l}$ $\mathrm{MgCl}_{2}$. After overnight incubation at $37^{\circ} \mathrm{C}$, one volume of $1 \mathrm{~mol} / /$ potassium carbonate was added at each sample, and absorbance of 0 -nitrophenol, the product resulting from the enzyme activity, was read at $420 \mathrm{~nm}\left(\mathrm{E}_{\mathrm{mM} \text { pH10 }} 21.3\right)$ ). $\beta$-gal was expressed as $\mu$ mols of $o$-nitrophenol/g tissue.

Measurement of GSH levels in mouse hearts. GSHtot concentration and oxidized GSH fraction (GSSG) were determined in heart extracts from young and old animals using the GSH reductase enzymatic method, ${ }^{44}$ based on the reaction between Ellman's reagent (DTNB) with GSH to form a spectrophotometric detectable product at $412 \mathrm{~nm}$. A standard curve of reduced GSh $(0-50 \mathrm{mM})$ was used to calculate GSH amounts in mice extracts. Briefly, frozen heart extracts from old and young animals were thawed $(50 \mu \mathrm{l})$ and subsequently assessed in phosphateEDTA buffer containing GSH reductase $(17 \mathrm{U} / \mathrm{ml})$, NADPH $(0.016 \mathrm{mg} / \mathrm{ml})$ and DTNB $(0.042 \mathrm{mg} / \mathrm{ml})$. To determine GSSG, a duplicate of each sample was previously incubated with $3 \mathrm{mmol} / /$ of 1 -methyl-2-vinylpyridinium triflate, a thiol-scavenging reagent, which rapidly scavenges reduced form of GSH without interfering with the enzyme activity. Results were expressed in $\mathrm{nmol} \mathrm{GSH} / \mathrm{mg}$ protein.

Differential quantitative mitochondrial proteomic analysis. Mitochondrial and microsomal fractions were isolated by differential centrifugation (as described above). Peptides and proteins were identified and quantified by differential high-throughput proteomic analysis performed by stable isotopic labeling using a previously described protocol. ${ }^{45-47}$ Changes in the abundance and composition of cysteine-thiol redox status of mitocondria and microsomal proteins were quantified using the GELSILOX methodology. ${ }^{48}$ Analyses of samples by LC-MS/MS were performed as previously described. ${ }^{49}$ Functional protein classification was done using the Gene Ontology database. Proteomics results were analyzed as previously described. ${ }^{50}$

Statistical analysis. Data are expressed as mean \pm S.E.M. For comparisons between two groups two-tailed Student's $t$-test for independent samples was used. For comparison of groups with more than one factor, a factorial ANOVA analysis was performed followed by post hoc comparisons when necessary. Differences of $P<0.05$ were considered statistically significant. When samples did not follow a normal distribution, the non-parametric test of median was used. All statistical analyses were performed with SPSS v.15 software (New York, NY, USA).

\section{Conflict of Interest}

The authors declare no conflict of interest.

Acknowledgements. The authors are grateful to Angeles Rojas for her excellent technical work. Supported by the Spanish Ministry of Science (SAF200803067, BIO2012-37926 and ProteoRed-PT13/0001/0017) and the Instituto de Salud Carlos III (RETICS-RECAVA RD12/0042/0021, RD12/0042/0056 and FIS-PI12100788). The CNIC is supported by the Spanish Ministry of Economy and Competitiveness and the Pro-CNIC Foundation.

1. Lloyd-Jones D, Adams RJ, Brown TM, Carnethon M, Dai S, De Simone G et al. Executive summary: heart disease and stroke statistics-2010 update: a report from the American Heart Association. Circulation 2010; 121: 948-954.

2. Boengler K, Schulz R, Heusch G. Loss of cardioprotection with ageing. Cardiovasc Res 2009; 83: 247-261.
3. Strait JB, Lakatta EG. Aging-associated cardiovascular changes and their relationship to heart failure. Heart Fail Clin 2012; 8: 143-164.

4. North BJ, Sinclair DA. The intersection between aging and cardiovascular disease. Circ Res 2012; 110: 1097-1108.

5. Terentyev D, Gyorke I, Belevych AE, Terentyeva R, Sridhar A, Nishijima Y et al. Redox modification of ryanodine receptors contributes to sarcoplasmic reticulum $\mathrm{Ca} 2+$ leak in chronic heart failure. Circ Res 2008; 103: 1466-1472.

6. Rosca MG, Vazquez EJ, Kerner J, Parland W, Chandler MP, Stanley W et al. Cardiac mitochondria in heart failure: decrease in respirasomes and oxidative phosphorylation. Cardiovasc Res 2008; 80: 30-39.

7. Sawyer DB, Siwik DA, Xiao L, Pimentel DR, Singh K, Colucci WS et al. Role of oxidative stress in myocardial hypertrophy and failure. J Mol Cell Cardiol 2002; 34: 379-388.

8. Szalai G, Csordas G, Hantash BM, Thomas AP, Hajnoczky G. Calcium signal transmission between ryanodine receptors and mitochondria. J Biol Chem 2000; 275: 15305-15313.

9. Rizzuto R, Pozzan T. Microdomains of intracellular $\mathrm{Ca} 2+$ : molecular determinants and functional consequences. Physiol Rev 2006; 86: 369-408.

10. Maack $C, O^{\prime}$ Rourke $B$. Excitation-contraction coupling and mitochondrial energetics. Basic Res Cardiol 2007; 102: 369-392.

11. Kohlhaas M, Maack C. Adverse bioenergetic consequences of $\mathrm{Na}+-\mathrm{Ca} 2+$ exchangermediated Ca2+ influx in cardiac myocytes. Circulation 2010; 122: 2273-2280.

12. Dhalla NS, Rangi S, Zieroth $S, X u$ YJ. Alterations in sarcoplasmic reticulum and mitochondrial functions in diabetic cardiomyopathy. Exp Clin Cardiol 2012; 17: 115-120.

13. Redpath CJ, Bou KM, Drozdzal G, Radisic M, McBride HM. Mitochondrial hyperfusion during oxidative stress is coupled to a dysregulation in calcium handling within a $\mathrm{C} 2 \mathrm{C} 12$ cell model. PLoS One 2013; 8: e69165.

14. Cerqua C, Anesti V, Pyakurel A, Liu D, Naon D, Wiche G et al. Trichoplein/mitostatin regulates endoplasmic reticulum-mitochondria juxtaposition. EMBO Rep 2010; 11: 854-860.

15. Chen Y, Csordas G, Jowdy C, Schneider TG, Csordas N, Wang W et al. Mitofusin 2containing mitochondrial-reticular microdomains direct rapid cardiomyocyte bioenergetic responses via interorganelle $\mathrm{Ca}(2+)$ crosstalk. Circ Res 2012; 111: 863-875.

16. Szabadkai G, Bianchi K, Varnai $P$, De Stefani D, Wieckowski MR, Cavagna D et al. Chaperone-mediated coupling of endoplasmic reticulum and mitochondrial $\mathrm{Ca} 2+$ channels. J Cell Biol 2006; 175: 901-911.

17. Yoshikane $\mathrm{H}$, Nihei $\mathrm{T}$, Moriyama $\mathrm{K}$. Three-dimensional observation of intracellular membranous structures in dog heart muscle cells by scanning electron microscopy. J Submicrosc Cytol 1986; 18: 629-636.

18. Csordas G, Renken C, Varnai P, Walter L, Weaver D, Buttle KF et al. Structural and functional features and significance of the physical linkage between $E R$ and mitochondria. J Cell Biol 2006; 174: 915-921.

19. Sharma VK, Ramesh V, Franzini-Armstrong C, Sheu SS. Transport of Ca2+ from sarcoplasmic reticulum to mitochondria in rat ventricular myocytes. J Bioenerg Biomembr 2000; 32: 97-104.

20. Eisner V, Csordas G, Hajnoczky G. Interactions between sarco-endoplasmic reticulum and mitochondria in cardiac and skeletal muscle - pivotal roles in $\mathrm{Ca}(2)(+)$ and reactive oxygen species signaling. J Cell Sci 2013; 126: 2965-2978.

21. van Vliet $A R$, Verfaillie $T$, Agostinis $P$. New functions of mitochondria associated membranes in cellular signaling. Biochim Biophys Acta 2014; 1843: 2253-2262.

22. Zima AV, Blatter LA. Redox regulation of cardiac calcium channels and transporters. Cardiovasc Res 2006; 71: 310-321.

23. Cooper LL, Li W, Lu Y, Centracchio J, Terentyeva R, Koren G et al. Redox modification of ryanodine receptors by mitochondria-derived reactive oxygen species contributes to aberrant Ca2+ handling in ageing rabbit hearts. J Physiol 2013; 591: 5895-5911.

24. Zhou L, Aon MA, Liu T, O'Rourke B. Dynamic modulation of Ca2+ sparks by mitochondrial oscillations in isolated guinea pig cardiomyocytes under oxidative stress. J Mol Cell Cardiol 2011; 51: 632-639.

25. Konstantinidis K, Lederer WJ, Rizzuto R, Kitsis RN. Mitofusin 2 joins the sarcoplasmic reticulum and mitochondria at the hip to sustain cardiac energetics. Circ Res 2012; 111: 821-823.

26. Ruiz-Meana M, Fernandez-Sanz C, Garcia-Dorado D. The SR-mitochondria interaction: a new player in cardiac pathophysiology. Cardiovasc Res 2010; 88: 30-39.

27. Ruiz-Meana M, Abellan A, Miro-Casas E, Agullo E, Garcia-Dorado D. Role of sarcoplasmic reticulum in mitochondrial permeability transition and cardiomyocyte death during reperfusion. Am J Physiol Heart Circ Physiol 2009; 297: H1281-H1289.

28. Abdallah Y, Iragi W, Said M, Kasseckert SA, Shahzad T, Erdogan A et al. Interplay between $\mathrm{Ca}(2+)$ cycling and mitochondrial permeability transition pores promotes reperfusioninduced injury of cardiac myocytes. J Cell Mol Med 2010.

29. Paillard M, Tubbs E, Thiebaut PA, Gomez L, Fauconnier J, Da Silva CC et al. Depressing mitochondria-reticulum interactions protects cardiomyocytes from lethal hypoxiareoxygenation injury. Circulation 2013; 128: 1555-1565.

30. Glancy B, Balaban RS. Role of mitochondrial $\mathrm{Ca} 2+$ in the regulation of cellular energetics. Biochemistry 2012; 51: 2959-2973.

31. Kohlhaas M, Liu T, Knopp A, Zeller T, Ong MF, Bohm M et al. Elevated cytosolic Na+ increases mitochondrial formation of reactive oxygen species in failing cardiac myocytes. Circulation 2010; 121: 1606-1613.

32. Brandes R, Bers DM. Simultaneous measurements of mitochondrial NADH and $\mathrm{Ca}(2+)$ during increased work in intact rat heart trabeculae. Biophys $J$ 2002; 83: 587-604. 
33. Hatano A, Okada J, Washio T, Hisada T, Sugiura S. Mitochondrial colocalization with Ca2+ release sites is crucial to cardiac metabolism. Biophys J 2013; 104: 496-504.

34. Fannin SW, Lesnefsky EJ, Slabe TJ, Hassan MO, Hoppel CL. Aging selectively decreases oxidative capacity in rat heart interfibrillar mitochondria. Arch Biochem Biophys 1999; 372 399-407.

35. Judge S, Jang YM, Smith A, Hagen T, Leeuwenburgh C. Age-associated increases in oxidative stress and antioxidant enzyme activities in cardiac interfibrillar mitochondria: implications for the mitochondrial theory of aging. FASEB J 2005; 19: 419-421.

36. Min CK, Yeom DR, Lee KE, Kwon HK, Kang M, Kim YS et al. Coupling of ryanodine receptor 2 and voltage-dependent anion channel 2 is essential for $\mathrm{Ca}(2)+$ transfer from the sarcoplasmic reticulum to the mitochondria in the heart. Biochem J 2012; 447: 371-379.

37. Decuypere JP, Monaco G, Missiaen L, De Smedt H, Parys JB, Bultynck G. IP et al. IP (3) receptors, mitochondria, and Ca signaling: implications for aging. J Aging Res 2011; 2011 920178.

38. Liu T, O'Rourke B. Regulation of mitochondrial $\mathrm{Ca} 2+$ and its effects on energetics and redox balance in normal and failing heart. J Bioenerg Biomembr 2009; 41: 127-132.

39. Ruiz-Meana M, Abellan A, Miro-Casas E, Garcia-Dorado D. Opening of mitochondria permeability transition pore induces hypercontracture in $\mathrm{Ca} 2+$ overloaded cardiac myocytes. Basic Res Cardiol 2007; 102: 542-552.

40. Palmer JW, Tandler B, Hoppel CL. Biochemical properties of subsarcolemmal and interfibrillar mitochondria isolated from rat cardiac muscle. J Biol Chem 1977; 252 8731-8739.

41. Matsuoka Y, Srere PA. Kinetic studies of citrate synthase from rat kidney and rat brain. J Biol Chem 1973; 248: 8022-8030.

42. Wieckowski MR, Giorgi C, Lebiedzinska M, Duszynski J, Pinton P. Isolation of mitochondriaassociated membranes and mitochondria from animal tissues and cells. Nat Protoc 2009; 4 $1582-1590$.

43. Lee BY, Han JA, Im JS, Morrone A, Johung K, Goodwin EC et al. Senescence-associated beta-galactosidase is lysosomal beta-galactosidase. Aging Cell 2006; 5: 187-195.

44. Tietze F. Enzymic method for quantitative determination of nanogram amounts of total and oxidized glutathione: applications to mammalian blood and other tissues. Anal Biochem 1969; 27: 502-522.
45. Bonzon-Kulichenko E, Perez-Hernandez D, Nunez E, Martinez-Acedo $P$, Navarro $P$ Trevisan-Herraz $\mathrm{M}$ et al. A robust method for quantitative high-throughput analysis of proteomes by 180 labeling. Mol Cell Proteomics 2011; 10: M110.

46. Navarro $P$, Vazquez J. A refined method to calculate false discovery rates for peptide identification using decoy databases. J Proteome Res 2009; 8: 1792-1796.

47. Navarro P, Trevisan-Herraz M, Bonzon-Kulichenko E, Nunez E, Martinez-Acedo P, Perez-Hernandez D et al. General statistical framework for quantitative proteomics by stable isotope labeling. J Proteome Res 2014; 13: 1234-1247.

48. Martinez-Acedo P, Nunez E, Gomez FJ, Moreno M, Ramos E, Izquierdo-Alvarez A et al. A novel strategy for global analysis of the dynamic thiol redox proteome. Mol Cell Proteomics 2012; 11: 800-813.

49. Lopez-Ferrer D, Ramos-Fernandez A, Martinez-Bartolome S, Garcia-Ruiz P, Vazquez J. Quantitative proteomics using 160/180 labeling and linear ion trap mass spectrometry. Proteomics 2006; 6: S4-S11.

50. Jorge I, Navarro P, Martinez-Acedo P, Nunez E, Serrano H, Alfranca A et al. Statistical model to analyze quantitative proteomics data obtained by $180 / 160$ labeling and linear ion trap mass spectrometry: application to the study of vascular endothelial growth factor-induced angiogenesis in endothelial cells. Mol Cell Proteomics 2009; 8 : $1130-1149$.

(c) (i) Cell Death and Disease is an open-access journal published by Nature Publishing Group. This work is licensed under a Creative Commons Attribution 4.0 International Licence. The images or other third party material in this article are included in the article's Creative Commons licence, unless indicated otherwise in the credit line; if the material is not included under the Creative Commons licence, users will need to obtain permission from the licence holder to reproduce the material. To view a copy of this licence, visit http://creativecommons.org/licenses/by/4.0

Supplementary Information accompanies this paper on Cell Death and Disease website (http://www.nature.com/cddis) 